\title{
Separation of Extracellular Vesicles by DNA-Directed Immunocapturing Followed by Enzymatic Release
}

Dario Brambilla, Laura Sola, Elisa Chiodi, Natasa Zarovni, Diogo Fortunato, Mattia Criscuoli, Vincenza Dolo, Ilaria Giusti, Valentina Murdica, Riccardo Vago, Marcella Chiari

Submitted date: 02/05/2020 - Posted date: 06/05/2020

Licence: CC BY-NC-ND 4.0

Citation information: Brambilla, Dario; Sola, Laura; Chiodi, Elisa; Zarovni, Natasa; Fortunato, Diogo; Criscuoli, Mattia; et al. (2020): Separation of Extracellular Vesicles by DNA-Directed Immunocapturing Followed by Enzymatic Release. ChemRxiv. Preprint. https://doi.org/10.26434/chemrxiv.12234683.v1

Extracellular vesicles (EVs) have attracted great interest among researchers due to their role in cell-cell communication, disease diagnosis, and drug delivery. In spite of their potential in the medical field, there is no consensus on the best method for separating microvesicles from cell culture supernatant and complex biological fluids. Obtaining a good recovery yield and preserving physical characteristics is critical for the diagnostic and therapeutic use of EVs. The separation is made complex by the fact that blood and cell culture media, contain a large number of nanoparticles in the same size range. Methods that exploit immunoaffinity capture provide high purity samples and overcome the issues of currently used separation methods. However, the release of captured nanovesicles requires harsh conditions that hinder their use in certain types of downstream analysis. Herein, a novel capture and release approach for small extracellular vesicles (sEVs), based on DNAdirected immobilization of antiCD63 antibody is presented. The flexible DNAlinker increases the capture efficiency and allows releasing of EVs by exploiting the endonucleasic activity of DNAse I. This separation protocol works under mild conditions, enabling the release of intact vesicles that can be successfully analyzed by imaging techniques. In this article sEVs recovered from plasma were characterized by established techniques for EVs analysis including nanoparticle tracking and transmission electron microscopy.

File list (2)

Separation of extracellular vesicles by DNA-directed immu... (3.08 MiB) view on ChemRxiv • download file Separation of extracellular vesicles by DNA-directed im... (111.24 KiB) view on ChemRxiv • download file 


\section{Separation of extracellular vesicles by DNA- directed immunocapturing followed by enzymatic release}

Dario Brambilla ${ }^{1^{*}}$, Laura Sola ${ }^{1}$, Elisa Chiodi ${ }^{1}$, Natasa Zarovni ${ }^{2}$, Diogo Fortunato ${ }^{2}$, Mattia Criscuoli ${ }^{2}$, Vincenza Dolo ${ }^{3}$, Ilaria Giusti ${ }^{3}$, Valentina Murdica ${ }^{4}$, Riccardo Vago $^{4,5}$, Marcella Chiari ${ }^{1}$

1) Institute of Chemical Science and Technology, National Research Council of Italy (CNR-SCITEC), Milan, Italy

2) Exosomics Siena S.p.A, Siena, Italy

3) Department of Life, Health and Environmental Sciences, University of L'Aquila, L'Aquila, Italy

4) Urological Research Institute, Division of Experimental Oncology, IRCCS San Raffaele Scientific Institute, Milan, Italy

5) Università Vita-Salute San Raffaele, Milan, Italy

*corresponding author: dario.brambilla@icrm.cnr.it 


\section{Abstract}

Extracellular vesicles (EVs) have attracted great interest among researchers due to their role in cell-cell communication, disease diagnosis, and drug delivery. In spite of their potential in the medical field, there is no consensus on the best method for separating microvesicles from cell culture supernatant and complex biological fluids. Obtaining a good recovery yield and preserving physical characteristics is critical for the diagnostic and therapeutic use of EVs. The separation is made complex by the fact that blood and cell culture media, contain a large number of nanoparticles in the same size range. Methods that exploit immunoaffinity capture provide high purity samples and overcome the issues of currently used separation methods. However, the release of captured nanovesicles requires harsh conditions that hinder their use in certain types of downstream analysis. Herein, a novel capture and release approach for small extracellular vesicles (sEVs), based on DNAdirected immobilization of antiCD63 antibody is presented. The flexible DNAlinker increases the capture efficiency and allows releasing of EVs by exploiting the endonucleasic activity of DNAse I. This separation protocol works under mild conditions, enabling the release of intact vesicles that can be successfully analyzed by imaging techniques. In this article sEVs recovered from plasma were characterized by established techniques for EVs analysis including nanoparticle tracking and transmission electron microscopy.

\section{Keywords}

Extracellular vesicles ï DNA-Directed Immobilization ï DNAse I ï Antibody ï Separation ï Immunocapturing ï Enzymatic cleavage ï Microarray

\section{Introduction}

Extracellular vesicles (EVs) are a powerful source of novel biomarkers in the diagnosis and prognosis of diseases. In spite of their potential in human diagnostics, there is no consensus on the best method for obtaining EVs in high yield, both from cell culture supernatant and complex biological fluids such as plasma. Isolation of EVs whilst preserving their physical characteristics is critical for certain types of downstream analyses which imply imaging of the nanoparticles. The majority of 
purification protocols exploit the physical properties of these vesicles to extract them from heterogeneous, biological samples. The most widely applied method, differential ultracentrifugation, comprises a series of increasing speed spins to selectively sediment bio-nanoparticles from solution ${ }^{1}$. Ultracentrifugation in a density gradient provides preparations that are free from contaminating cellular debris, but this method is not suited for high-throughput applications ${ }^{2}$.

Ultrafiltration or size exclusion chromatography exploits size difference for the isolation. Ultrafiltration is faster than ultracentrifugation but the use of centrifugal force may result in the deformation and breaking up of large vesicles potentially altering the results of downstream analysis ${ }^{3}$. Size exclusion chromatography (SEC) has little risk for damage or aggregation of EVs since it relies on gravity flow. However, while SEC purifies EVs, it also dilutes them. Therefore, the method is not suitable for harvesting EVs from cell culture media, where they are often less concentrated than in plasma ${ }^{4}$.

Several commercial kits, such as the Invitrogen Total Exosome Isolation Kit (Life Technologies, USA) and ExoSpin Exosome Purification Kit (Cell Guidance Systems, USA), add poly-ethylene glycol or similar substances to promote sedimentation of exosomes from solution during low speed centrifugation $\left(10,000\right.$ ï 20,000 × g) ${ }^{5 i 7}$. However, with these methods the presence of contaminating cellular and protein debris has been noted.

In general, a significant problem in small and large EVs isolation is that both, blood and cell culture media, contain large numbers of nanoparticles (some non-vesicular) in the same size range as extracellular vesicles ${ }^{8}$. Therefore separation by physical characteristics is not possible.

To overcome this problem, methods that exploit immunoaffinity interactions between proteins and receptors on the membrane of exosomes and their antibodies have been proposed ${ }^{9}$. Ideally, antigens for immuno isolation are solely expressed or highly concentrated on the surface of exosomes from specific biological sources.

The aim of this work was to develop an immunoaffinity method for rapid isolation of EVs that facilitate their recovery as intact vesicles. In particular, we focused on sEVs (30-200 nm in diameter) because of their well established potential in therapeutic and diagnostic fields ${ }^{10,11,12,13}$. The release of intact SEVs is enabled by the strategy used for the immobilization of antibodies on magnetic particles that is based on the so called DNA directed immobilization (DDI) strategy. DDI is a chemically mild and 
highly efficient method for generating (micro)structured patterns of proteins on surfaces using surface-bound capture oligonucleotides to selectively bind proteins tagged with complementary oligonucleotides ${ }^{14}$. The method was initially introduced to fabricate protein microarrays. It has been proven that DNA linkers are excellent spacers that enhance the availability of antibodies binding sites for analyte capture by decreasing the steric hindrance ${ }^{15}$. This feature has been recently exploited for the multiplexed capturing of viruses in an interferometric technique called single particle interforemetric reflectance imaging sensor (SP-IRIS) ${ }^{16}$. Although this method aims to separate EVs from complex biological fluids in physiological conditions, it offers a number of advantages for multiplex analysis and release. Using oligonucleotide tags with different sequence it would be possible to release EVs subtypes captured by oligonucleotides bearing sequences recognized by specific restriction enzymes. Several methods exist to conjugate the ligand (in general an antibody, a protein or a peptide) with DNA ${ }^{17}$ including non-covalent strategies, such as coupling via biotin-streptavidin ${ }^{18}$ or covalent conjugation, using e.g. thiolmaleimide chemistry ${ }^{19}$. The approach used here is based on click chemistry, namely the strain-promoted azide-alkyne cycloadditon (SPAAC) reaction ${ }^{20}$. This bioorthogonal reaction between a dibenzocyclooctine (DBCO) modified antibody and an azide-modified oligonucleotide provides an easy and efficient protocol for the conjugation of antibodies to a single stranded DNA (ssDNA) fragment. Besides increasing capturing efficiency, DDI allows facile release of EVs as the double stranded DNA linker can be cleaved by an enzymatic reaction catalyzed by DNAse I. Conventional methods to release EVs based on the disruption of antibody-antigen bonds cause severe damages to EVs as they require the use of buffers with low pHs and/or detergents. Moreover, methods based on DNA denaturation, that require changes of physical properties (e.g. heating and sonication) or chemical conditions (such as alkaline treatment, formamide and DMSO) are not compatible with the stability of EVs. We demonstrate that SEVs specifically captured using antibodies tagged with different oligonucleotides that are complementary to various sequences immobilized on the same surface, are intact when released by cutting the DNA linker enzymatically with DNAse $\mathrm{I}^{21}$ and can be analyzed by imaging techniques. 


\section{Materials and Methods}

We have submitted all relevant data of our experiments to the EV-TRACK knowledgebase (EV-TRACK ID: EV190054) ${ }^{22}$.

\subsection{Materials}

Ammonium sulfate $\left(\left(\mathrm{NH}_{4}\right)_{2} \mathrm{SO}_{4}\right)$, dibenzocyclooctyne-N-hydroxysuccinimidyl ester (DBCO-NHS ester), phosphate buffer saline tablets (PBS), Tris, 37\% chloric acid $(\mathrm{HCl})$, sodium phosphate $\left(\mathrm{Na}_{3} \mathrm{PO}_{4}\right)$, sucrose monolaurate, sodium chloride $(\mathrm{NaCl})$, magnesium chloride $\left(\mathrm{MgCl}_{2}\right)$, calcium chloride $\left(\mathrm{CaCl}_{2}\right)$, Tween 20 , glycerol, sodium dodecyl sulfate (SDS), bromophenol blue, DNAse I from bovine pancreas, IgGs from rabbit serum, ethanolamine, trehalose dihydrate and Amicon Ultra centrifugal filters (MWCO 10K and 30K) were purchased from Sigma Aldrich (St. Louis, MO, USA). All solvents were used as received. Sodium azide free $\lg G$ antibodies: mouse antihuman CD9 (clone MEM-61) and mouse anti-human CD63 (clone MEM-259) were provided by HansaBioMed Life Sciences Ltd (Tallinn, Estonia). CellTraceÊ CFSE reagent was purchased from Thermofisher Scientific (Waltham, MA, USA). Alexa Fluor® 488-conjugated antiCD63 antibody was purchased from R\&D Systems (Minneapolis, MN, USA). Phycoerythrin (PE) labeled antiCD63 antibody was purchased from Exbio, Vestec, Czech Republic). Unreacted CFSE reagent and fluorescent antibodies were removed using Nanosep MWCO $300 \mathrm{~K}$ spin columns (Pall Corporation, New York, USA). Amine magnetic beads (0.5 $\mu \mathrm{m}$ in diameter) were purchased from Abraxis Inc. (Warminster, PA, USA). Oligonucleotides were synthesized by MWG-Biotech AG (Ebevsberg, Germany): see Supplementary for oligonucleotide sequences. ssDNA-TAGs were modified with a C6-azido linker at the 5' end, while ssDNA-PROBEs and COCU8 were modified with a C6 amino or biotin linker at 5ôend. Oligonucleotides were freeze-dried and resuspended in de-ionized water (DI water) at a final concentration of $100 \mu \mathrm{M}$ before use. Negative controls were used in each experiment. In antibody DNA-directed immobilization experiments COCU8 was used as a negative control to demonstrate that the ssDNA modified antibody is specifically captured only by the oligonucleotide sequence complementary to the tag. In experiments involving EVs, polyclonal rabbit IgG was used as negative control. Untreated silicon chips with $100 \mathrm{~nm}$ thermal grown oxide 
$(14 \times 14 \mathrm{~mm})$ and with $110 \mathrm{~nm}$ thermal grown oxide $(12.5 \times 25 \mathrm{~mm})$ were supplied by SVM, Silicon Valley Microelectronics Inc. (Santa Clara, CA, USA). NV10B silicon chips were supplied by NanoView Biosciences (Boston, MA, USA). Both chips were pretreated using a HARRICK Plasma Cleaner, PDC-002 (Ithaca, NY, USA), connected to an oxygen line. MCP-2 was purchased from Lucidant Polymers Inc. (Sunnyvale, CA, USA). Spotting is performed using SciFLEXARRAYER S12 (Scienion, Berlin, Germany). Bradford protein quantification analysis was performed using a Jasco V-530 UV/VIS Spectrophotometer and data were analyzed using Spectra Manager software 1.54 (Jasco, MD, USA). Centrifugation was carried out using Eppendorf MiniSpin (Eppendorf, Hamburg, Germany). The efficiency of the DNA directed immobilization of antibodies was tested by real-time IRIS device, using a low-magnification IRIS setup designed to perform in-liquid measurements. The instrument is fully described in ${ }^{23,24}$. Briefly, this setup takes advantage of commonpath interference to enhance the biomass accumulation on the surface. The thickness of the silicon oxide layer of the chips $(110 \mathrm{~nm})$ is optimized to obtain constructive interference, which enhances the reflectance signal. The images were acquired through Micro-Manager software and analyzed in ImageJ to obtain the reflectance values. Custom-made MATLAB software was used to convert the raw signal data to mass density. The analysis is illustrated in detail in ${ }^{25}$. Interferometric analyses of EVs were performed exploiting SP-IRIS technique using ExoViewÊ R100 for image acquisition and nanoViewer 2.6.0 software for analysis (NanoView Biosciences Inc., MA, USA). This instrument measures the number of single particles (ranging from 50 to $200 \mathrm{~nm}$ in diameter) captured on the chip surface as well as their size distribution. Nanoparticle Tracking Analysis was performed with NanoSight NS300 using 3.2 Dev Build 3.2.16 software (Malvern Instruments Ltd, Malvern, United Kingdom). Nanoscale flow cytometry (nanoFCM) measurements were carried out using flow nanoanalyser model U30E (nanoFCM Co. LTD, Nottingham, UK), a dedicated nanoparticle flow analyser, which detects down to 40$45 \mathrm{~nm}$ EVs at the single-particle level. Data were analysed using the NF Profession software version 1.0. Spectrophotometric readings of the same samples were obtained using CLARIOstar Plus - BMG430101(BMG Labtech, Ortenberg, Germany) and MARS Data Analysis Software. 


\subsection{Antibody functionalization with ssDNA}

As reported in Figure 1, antibodies directed against EV-related tetraspanins (CD9 and CD63) were modified with a linker bearing $\mathrm{N}$-oxysuccinimide ester at one end and dibenzocyclooctine (DBCO) at the other end to allow their binding to azido modified oligonucleotides.

2.2.1 Synthesis of ssDNA-antiCD63: $4.4 \mu \mathrm{L}$ of a $4 \mathrm{mM}$ PBS solution of DBCO-NHS ester were added to $200 \mu \mathrm{L}$ of sodium azide-free mouse anti-human CD63 IgG (0.70 $\mathrm{mg} / \mathrm{ml}$ ) and the solution was allowed to react for $30 \mathrm{~min}$ at room temperature. The reaction was quenched by adding $20 \mu \mathrm{L}$ of $1 \mathrm{M}$ TRIS- $\mathrm{HCl}, \mathrm{pH} 8.0$, and the unreacted ester was removed, through centrifugation over an Amicon Ultra 10K filter (3 min at $12,000 \mathrm{xg}$ ). The eluted solution was discarded and the protein was recovered in 200 $\mu \mathrm{L}$ of PBS. The oligonucleotide ssDNA-TAG-63 (8.2 $\mu \mathrm{L}, 100 \mu \mathrm{M})$ was added to 200 $\mu \mathrm{L}$ of DBCO-modified antibody $(0.66 \mathrm{mg} / \mathrm{ml})$ and the strain-promoted 1,3-dipolar cycloaddition of cycloalkynes to azide reaction was carried out overnight at $4^{\circ} \mathrm{C}$. The unreacted oligonucleotide was eliminated through centrifugation over an Amicon Ultra $30 \mathrm{~K}$ filter by centrifugation for $2 \mathrm{~min}$ at 12,000xg. After the final purification, 200 $\mu \mathrm{L}$ of ssDNA-modified antiCD63 $(0.47 \mathrm{mg} / \mathrm{ml})$ were obtained. The antibody concentration was determined before each step using a Bradford assay. The sample (3 $\mu \mathrm{L}$ ) was added to a solution of $2.4 \mathrm{~mL}$ of water and $0.6 \mathrm{~mL}$ of Bradford Reagent. The absorbance at $595 \mathrm{~nm}$ was measured using a Jasco V-530 UV/VIS Spectrophotometer.

2.2.2 Synthesis of ssDNA-antiCD9: an identical procedure was used to tag CD9: 3.8 $\mu \mathrm{L}$ of DBCO-NHS ester, $4 \mathrm{mM}$, were added to $200 \mu \mathrm{L}$ of sodium azide-free mouse Anti-Human CD9 $\mathrm{lgG}(0.61 \mathrm{mg} / \mathrm{ml})$ and the solution was allowed to react for $30 \mathrm{~min}$ at room temperature. Once the reaction was quenched and the unreacted ester removed, $7.4 \mu \mathrm{L}$ of SsDNA-TAG-9 $100 \mu \mathrm{M}$ were added to $200 \mu \mathrm{L}$ of DBCO-modified antibody $(0.59 \mathrm{mg} / \mathrm{ml})$ and the SPAAC reaction was carried out overnight at $4^{\circ} \mathrm{C}$. After final purification, $200 \mu \mathrm{L}$ of ssDNA-modified antiCD9 $(0.42 \mathrm{mg} / \mathrm{ml})$ were obtained. 
2.2.3 Synthesis of ssDNA-rabbit IgG: an identical procedure was used to tag polyclonal rabbit IgG: $2.1 \mu \mathrm{L}$ of DBCO-NHS ester, $4 \mathrm{mM}$, were added to $100 \mu \mathrm{L}$ of sodium azide-free rabbit $\lg G(0.65 \mathrm{mg} / \mathrm{ml})$ and the solution was allowed to react for $30 \mathrm{~min}$ at room temperature. Once the reaction was quenched and the unreacted ester removed, $3.66 \mu \mathrm{L}$ of ssDNA-TAG-63 $100 \mu \mathrm{M}$ were added to $100 \mu \mathrm{L}$ of DBCOmodified antibody $(0.55 \mathrm{mg} / \mathrm{ml})$ and the SPAAC reaction was carried out overnight at $4^{\circ} \mathrm{C}$. After final purification, $100 \mu \mathrm{L}$ of ssDNA-rabbit $\lg \mathrm{G}(0.55 \mathrm{mg} / \mathrm{ml})$ were obtained.

\subsection{DNA-Directed Immobilization (DDI) of antibodies on silicon chips.}

2.3.1 Probe spotting on the surface of microarray: both protein and oligonucleotide solutions were prepared. Proteins were dissolved at $2 \mathrm{mg} / \mathrm{mL}$ in $50 \mathrm{mM}$ trehalose in PBS. Amino-modified oligonucleotides complementary to the antibody tag (ssDNAPROBES) were dissolved at different concentrations $(0.5,5,10$ and $25 \mu \mathrm{M})$ in a solution of $150 \mathrm{mM}$ sodium phosphate buffer containing $0.01 \%$ sucrose monolaurate at $\mathrm{pH}$ 8.5. The probes were then spotted onto the surface of different silicon/silicon oxide chips, depending on the detection technique used. In particular, chips with a $100 \mathrm{~nm}$ thick $\mathrm{SiO}_{2}$ layer were used for fluorescence detection, while chips with 110 $\mathrm{nm}$ and $55 \mathrm{~nm}$ oxide layers were used for IRIS and SP-IRIS measurements respectively. All chips were coated with copoly (DMA-NAS-MAPS), a polymer commercially available with the trade name of MCP-2 (Lucidant Polymers Inc., Sunnyvale CA, USA). MCP-2 is a ter-copolymer of $\mathrm{N}, \mathrm{N}$-dymethilacrylamide (DMA) (97\% in moles), $N$-acryloyloxysuccinimide (NAS) (2\% in moles) and 3 (trimethoxysilyl)propyl methacrylate (MAPS) (1\% in moles), which forms a 3-D layer for the immobilization of antibodies with retained capture efficiency and suppression of non-specific binding ${ }^{26}$.

Chips were spotted using a noncontact microarray spotter (sciFLEXARRAYER S12, Scienion, Berlin) equipped with an $80 \mu \mathrm{m}$ nozzle. $400 \mathrm{pL}$ of solution were spotted at room temperature and $65 \%$ humidity. Immediately after spotting, the chips were stored overnight in a sealed chamber filled at the bottom with sodium chloride saturated water $\left(40 \mathrm{~g} / 100 \mathrm{~mL} \mathrm{H}_{2} \mathrm{O}\right)$. After incubation, the chips were treated with a blocking solution of ethanolamine $(50 \mathrm{mM}$ in $0.1 \mathrm{M} \mathrm{Tris/HCl}$ buffer $\mathrm{pH} 9)$, at room 
temperature for $1 \mathrm{~h}$. Then chips were rinsed with bidistilled water and dried under nitrogen stream.

2.3.2 Evaluation of DNA-Directed Immobilization efficiency with real-time IRIS measurements: Different concentrations of ssDNA-PROBE-9 and ssDNA-PROBE-63 $(0.5,5,10$ and $25 \mu \mathrm{M})$ antiCD9, antiCD63 and a $10 \mu \mathrm{M}$ solution of SsDNA (COCU8 10) that does not bind the ssDNA-tagged antibodies, were deposited on a silicon chip as described in section 2.3.1. Once ready, the chip was assembled with an adhesive spacer and an AR coated glass slide, to form a chamber for in-flow measurements ${ }^{23}$. The cartridge thus obtained was loaded into the Interferometric Reflectance Imaging Sensor (IRIS) instrument and PBS was flowed for $15 \mathrm{~min}$ to stabilize the probes. A solution of SsDNA-antiCD9 and ssDNA-antiCD63, each at a concentration of $0.5 \mu \mathrm{g} / \mathrm{mL}$, was then injected into the system and recirculated for 20 min at an average flow-rate of $200 \mu \mathrm{L} / \mathrm{min}$. PBS was then flowed for $20 \mathrm{~min}$ at the same flow-rate as the sample. The same procedure was repeated twice with different antibodies concentrations (i.e. $5 \mu \mathrm{g} / \mathrm{mL}$ and $10 \mu \mathrm{g} / \mathrm{mL}$ ).

Interferometric images were acquired during the whole process with a blue LED light $(465 \mathrm{~nm})$. Four-color images, used to generate a look-up table for the conversion to mass density were acquired at the beginning and at the end of each step ${ }^{25}$.

2.3.3 Extracellular Vesicles capture: five $\mu \mathrm{M}$ ssDNA-PROBE-63, antiCD63 and polyclonal rabbit IgG (as negative control) were spotted on three SP-IRIS chips as previously described (see section 2.3.1). Chips were incubated with a $5 \mu \mathrm{g} / \mathrm{mL}$ solution of ssDNA-antiCD63 for $1 \mathrm{~h}$ at room temperature to perform DDI. Chips were washed $10 \mathrm{~min}$ in PBS, rinsed with bidistilled water and dried. Prescan images of the chips were acquired. Chips were incubated with a $1 * 10^{9}$ particles $/ \mathrm{mL}$ solution of EVs isolated from HEK-293 cell culture media as described in 2.4.1 (isolated sample was diluted in PBS to reach the desired concentration). The incubation was carried out at room temperature in a humid chamber for $2.5 \mathrm{~h}$. The chips were then washed for 10 min in PBS, rinsed with bidistilled water and dried. Finally, they were analyzed using ExoView R100. 
2.3.4 Release of DNA-directed antibodies from microarray: $5 \mu M$ ssDNA-PROBE-63 spots were deposited on 3 SP-IRIS chips as previously described (see section 2.3.1). Chips were incubated with a $5 \mu \mathrm{g} / \mathrm{mL}$ solution of ssDNA-antiCD63 for $1 \mathrm{~h}$ at room temperature to perform DDI. Chips were washed 10 min in PBS, rinsed with bidistilled water and dried. Prescan images of the chips were acquired. . The chips were then incubated with a $250 \mathrm{mKunitz} / \mu \mathrm{L}$ solution of DNAse I from bovine pancreas in $10 \mathrm{mM}$ Tris/ $\mathrm{HCl} \mathrm{pH} 7.5$ buffer, containing $5 \mathrm{mM} \mathrm{MgCl} 2$ and $130 \mu \mathrm{M}$ $\mathrm{CaCl}_{2}$. The incubation was performed in a humid chamber at $37^{\circ} \mathrm{C}$ for $1 \mathrm{~h}$, and then the chips were washed $15 \mathrm{~min}$ in washing buffer $(50 \mathrm{mM}$ Tris/ $\mathrm{HCl} \mathrm{pH} \mathrm{9,} 250 \mathrm{mM}$ $\mathrm{NaCl}, 0.05 \%$ Tween 20 ), rinsed with bidistilled water and dried. Finally postscan images were acquired.

\subsection{Extracellular vesicles separation using DNA-Directed Immobilization of antiCD63 on magnetic beads.}

2.4.1 Separation of EVs from HEK-293 cell culture medium by ultracentrifugation: HEK-293 cells were seeded on $150 \mathrm{~mm}$ dishes in DMEM culture medium supplemented with $10 \%$ EV-depleted FCS, $2 \mathrm{mM} \mathrm{L-Glutamine,} 100 \mathrm{U} / \mathrm{mL}$ penicillin and $100 \mathrm{gg} / \mathrm{mL}$ streptomycine-sulphate. After $72 \mathrm{~h}$ incubation, the culture medium was collected and centrifuged (1500 rpm) for $25 \mathrm{~min}$ to remove cell debris. The obtained supernatant was filtered through $0.22 \mathrm{\varepsilon m}$ filter and then ultracentrifugated at $150.000 \mathrm{xg}$ for 2 hours at $4^{\circ} \mathrm{C}$ (Beckman Coulter). The EV-containing pellet was resuspended in PBS.

2.4.2 EVs staining using CFSE: After assessing particle concentration by unstained nanoFCM measurement, each CFSE staining reaction consisted of $1 \times 10^{9}$ particles, with CellTraceÊ CFSE reagent at 10uM in PBS following manufacturers protocol. Excess of dye was removed by performing buffer exchange with PBS, using Nanosep MWCO 300K spin columns.

2.4.3 Plasma collection: Blood samples were obtained from healthy blood donors in non fasting conditions at the Department of Clinical Immunology at Aalborg University Hospital. Blood samples were collected in a bag system LQT6283LE 
(Macopharma, France) using CPDA as anticoagulant, and centrifuged at $4800 \times \mathrm{g}$ for $10 \mathrm{~min}$ to separate plasma. The plasma was removed, aliquoted and stored at $40^{\circ} \mathrm{C}$. Before analysis plasma was centrifuged at $10.000 \mathrm{x} \mathrm{g}$ for $10 \mathrm{~min}$ and then filtered through $0.22 \mu \mathrm{m}$ syringe filters (Corning, NY, USA).

2.4.4 Magnetic beads functionalization: DNA tagged antibodies were immobilized on the surface of magnetic beads and used to immunocapture EVs. Prior to their use, streptavidin-coated magnetic beads (Dynabeads M-270 Streptavidin, Invitrogen) were washed three times with binding and washing buffer (B\&W) $(5 \mathrm{mM}$ Tris- $\mathrm{HCl}, \mathrm{pH}$ 7.5; $0.5 \mathrm{mM}$ EDTA; $1 \mathrm{M} \mathrm{NaCl}$ ) according to the manufacturer $\hat{\mathbf{s}}$ protocol. Then 500 $\mu \mathrm{g}$ of beads were added to $100 \mu \mathrm{L}$ of $1 \mu \mathrm{M}$ biotinylated ssDNA-Probe-63 solution. The suspension was stirred for $30 \mathrm{~min}$ at $23^{\circ} \mathrm{C}$, then the solution was removed and the beads were washed twice with B\&W buffer, then once with PBS.

Oligonucleotide modified beads $(500 \mu \mathrm{g})$ were incubated with $100 \mu \mathrm{L}$ of ssDNAantiCD63 antibody $(160 \mu \mathrm{g} / \mathrm{mL})$ for $1 \mathrm{~h}$ at $25^{\circ} \mathrm{C}$, then the solution was removed and the beads were washed twice in PBS

2.4.5 Capture and release of EVs from magnetic beads: DNA-directed SSDNAantiCD63 functionalized magnetic beads $(500 \mu \mathrm{g})$ were incubated with $250 \mu \mathrm{L} \mathrm{EV}$ containing samples (human blood plasma or EVs isolated from HEK-293 cell line by ultracentrifugation). After $2.5 \mathrm{~h}$ of incubation at room temperature and $1400 \mathrm{rpm}$, the surnatant was removed and the beads were washed twice with PBS. Then beads were incubated with $50 \mu \mathrm{L}$ of $250 \mathrm{mKunitz} / \mu \mathrm{L}$ solution of DNAse I from bovine pancreas in $10 \mathrm{mM}$ Tris/ $\mathrm{HCl}, \mathrm{pH} 7.5$ buffer, containing $5 \mathrm{mM} \mathrm{MgCl}_{2}$ and $130 \mu \mathrm{M}$ $\mathrm{CaCl}_{2}$. At the end of the incubation, which was performed at $37^{\circ} \mathrm{C}$ for $1 \mathrm{~h}$ at 1400 rpm, the beads were separated using a magnetic stand and the buffer was recovered and used in subsequent analysis.

\subsection{Extracellular Vesicles separation by conventional techniques}

2.5.1 Magnetic beads for conventional immunocapturing (C/C): Carboxylated magnetic beads (Abraxys Inc., Warminster, PA, USA) were covalently functionalized with antiCD63 (clone MEM259, HansaBioMed, Estonia) via conventional amine coupling. $10 \mu \mathrm{L}$ of $2.5 \mathrm{mg} / \mathrm{mL}$ functionalized magnetic beads $(0.5 \mu \mathrm{m}$ in diameter $)$ 
were added to $500 \mu \mathrm{L}$ of plasma and incubated for $4 \mathrm{~h}$ at $25^{\circ} \mathrm{C}$ and $1400 \mathrm{rpm}$. Then the beads were washed twice with $1 \mathrm{~mL}$ of PBS. To release EVs, $10 \mu \mathrm{L}$ of elution buffer (HansaBioMed, Tallinn, Estonia) was added to the beads and the solution was vortexed for $30 \mathrm{~s}$. After $5 \mathrm{~min}$, the solution was vortexed again for $30 \mathrm{~s}$ and finally 40 $\mu \mathrm{L}$ of PBS were added.

2.5.2 Ultracentrifugation: Plasma sample was centrifuged at $10000 \times \mathrm{g}$ for $10 \mathrm{~min}$ to remove debris and aggregates. The supernatant was collected, diluted 1:2 with PBS and filtered through $0.22 \mu \mathrm{m}$ syringe filters (Corning, NY, USA). The clarified medium was then centrifuged at $150.000 \times \mathrm{g}$ at $4^{\circ} \mathrm{C}$ for 90 min (Beckman Coulter TL-100 Ultracentrifuge, TLA-100.3 fixed angle rotor) to sediment extracellular vesicles. The supernatant was carefully removed, and the pellet was resuspended in PBS and stored at $-20^{\circ} \mathrm{C}$ until used.

\subsection{Characterization of released extracellular vesicles}

2.6.1 Nanoparticle Tracking Analysis: All samples were analyzed using Nanosight NS300 (Malvern Panalytical, Malvern, UK). Videos were analyzed by the in-build NanoSight Software NTA 3.2 Dev Build 3.2.16. The Camera type, Camera level, and Detect Threshold were sCMOS, 14 and 4, respectively. The number of completed tracks in NTA measurements was 5 (a 60 seconds movie was registered for each measurement). All samples were diluted in PBS to a final volume of $1 \mathrm{~mL}$. The ideal concentration was assessed by pre-testing the optimal particle per frame value (20100 particles per frame).

2.6.2 Nanoscale Flow Cytometry (nanoFCM) Analysis: Optimizations performed to achieve increased sensitivity in detecting single nanoparticles in flow have previously been described ${ }^{27 i 29}$. A continuous wave $40 \mathrm{~mW} 488$ laser excitation source causes nanoparticles to scatter and emit light, which is then split by dichroic beam splitters to arrive at three single photon counting modules (SPCM). Bandpass filters placed before each SPCM detector, allow to simultaneously detect side scatter (SS ï 488/10) and fluorescence (green channel ï 525/40) of a single event. For each channel, thresholds were set to three times the standard deviation of detected background signal. Events and respective intensities were recorded for each peak 
higher than set thresholds. Samples were read for 1 minute at a rate under 12000 events/min to avoid swarm effect and consequently, co-detection of two or more events. Size and concentration estimations were performed based on previous research ${ }^{27 i} 29$, using a Silica nanospheres cocktail $(68 \pm 2 \mathrm{~nm}, 91 \pm 3 \mathrm{~nm}, 113 \pm 3$ $\mathrm{nm}$, and $155 \pm 3$ nm; S16M-Exo; nanoFCM Co. LTD, UK) and 200nm Counting standard nanospheres (S08210; nanoFCM Co. LTD, UK). For staining reactions with primary fluorescent antibodies, $1 \times 10^{9}$ particles were incubated with optimized concentrations of AlexaFluor ${ }^{\circledR}$ 488-conjugated antiCD63 (diluted 1:5 in PBS) or phycoerythrin lalbeled antiCD63 (diluted 1:25 in PBS) for $1 \mathrm{~h}$ at $37 \mathrm{C}$. Unbound antibodies were washed off by performing buffer exchange with PBS, using Nanosep MWCO $300 \mathrm{~K}$ spin columns.

2.6.3 Spectrophotometric Analysis: For each timepoint, 100uL of sample were loaded in triplicate or single into 96-well black opaque plates (OptiPlate-96, Black Opaque 96-well Microplate; Perkin Elmer). For each measurement, gain was adjusted automatically by the instrument and software to detect $80-90 \%$ of the maximum signal, in the most fluorescent well. The results are always expressed as ratio to background or fold change.

2.6.4 TEM Microscopy: Transmission electron microscopy (TEM) was performed on isolated SEVs, resuspended in PBS, to analyze their ultrastructural morphology. According to proper dilutions, the samples were adsorbed to 300 mesh carboncoated copper grids (Electron Microscopy Sciences, Hatfield, PA, USA) for 5 min in a humidified chamber at room temperature. SEVs on grids were then fixed in $2 \%$ glutaraldehyde (Electron Microscopy Sciences, Hatfield, PA, USA) in PBS for $10 \mathrm{~min}$ and then briefly rinsed in milli-Q water. Grids with adhered $\mathrm{SEV}$ s were examined with a Philips CM 100 transmission electron microscope TEM at 80kV, after negative staining with $2 \%$ phosphotungstic acid, brought to $\mathrm{pH} 7.0$ with $\mathrm{NaOH}$. The images were captured by a Kodak digital camera.

2.6.5 Capture on Microarray Slide: SEVs separated with magnetic beads functionalized using DDI approach as reported in paragraph 2.4.2, were analyzed by SP-IRIS instrument using the commercial microarray silicon chips (ExoView ${ }^{\mathrm{TM}}$ 
Tetraspanin Kit, NanoView Biosciences, USA). The incubation was carried out for $2.5 \mathrm{~h}$ at room temperature, and then chips were washed for $10 \mathrm{~min}$ in the washing buffer of the kit, rinsed with bidistilled water and dried. Finally, chips were scanned using SP-IRIS technology.

\section{Results and discussion}

The aim of the work was to develop a reversible immuno-capturing strategy to allow the collection of EVs on magnetic beads and, subsequently, their release from the surface in response to a proper stimulus.

The most widespread method to covalently immobilize antibodies on solid supports exploits surfaces functionalized with activated carboxylic acids that react with amino groups naturally exposed on proteins forming amido bonds. Although this approach is well described and widely applied, it is not the best choice when the target is a nano-bioparticle that must be captured reversibly. In the specific case of EVs separation, the strong acidic buffers and/or detergents required to release an antigen from its antibody damage these nanoparticles impairing certain types of downstream analysis ${ }^{30}$. Since our purpose was to release intact vesicles, we introduced the socalled DNA directed immobilization (DDI) strategy for the functionalization of magnetic beads. DDI is a chemically mild approach that is used to anchor proteins on solid surfaces through a DNA-linker. In this approach, the surface and the antibody are functionalized with complementary oligonucleotides and the immobilization occurs upon interaction of the two complementary strands.

DDI is an elegant approach that overcomes some of the issues related to protein microarrays fabrication and improves probe availability. In addition to these features, we have selected this method mainly for the reversible character of the DNA-linker that can be denatured (by changing temperature or ionic strength of the medium) or cleaved using enzymes, causing the release of the target-probe complex from the surface in mild conditions.

Owing to the difficulties in designing a DNA sequence that captures the probe at room temperature but can be denatured at maximum $37^{\circ} \mathrm{C}$ and to the impossibility of using low ionic strength buffers that cause EVs disruption, we chose to cleave the double stranded DNA linker, by means of an enzymatic reaction catalyzed by DNAse I. 
Antibodies directed against EVsôsurface proteins, in particular tetraspanins CD9 and CD63, were tagged with ssDNA-TAG-9 and ssDNA-TAG-63, respectively. The synthetic route is depicted in Figure.1. The first step is the introduction of dibenzocyclooctine (DBCO) on the antibody using a bifunctional linker, allowing the further reaction with an azido-modified oligonucleotide.

In order to assess the effectiveness of the method, a set of microarray tests was devised and the experimental parameters optimized. First, the antibody immobilization density was evaluated with a real-time IRIS experiment. Different concentrations of ssDNA-PROBE-9 and ssDNA-PROBE-63, antiCD9, antiCD63 and COCU8 (a sequence of DNA used as negative control) were spotted on a silicon chip as described in section 2.3.1 and the chip was mounted in a microfluidic chamber on which different concentrations of ssDNA-antiCD9 and ssDNA-antiCD63 were flown. The working principle and technical details about the IRIS instrument are fully described in ${ }^{23,24}$. Briefly, the optical setup can be described as a simple reflecting microscope. Common path interference is achieved by illuminating a $\mathrm{Si} / \mathrm{SiO}_{2}$ chip from the top with a combination of four-colors LEDs. The thickness of the oxide is chosen so that the shift of the reflectance curve due to biomass accumulation on the chip shall be directly correlated to the thickness of the transparent layer. The biomass thickness thus obtained is then converted to mass density, with a $\mathrm{pg} / \mathrm{mm}^{2}$ sensitivity ${ }^{25}$. The results in terms of density of immobilized antibody are shown in Figure 2. As expected, no mass is accumulated on the negative control (COCU8) and on antibodies immobilized through conventional amine coupling, while the mass density increases on the spots of ssDNA-probes, confirming the success of DDI.

The amount of antibody captured depends on the density of SSDNA-PROBE which in turn depends on the concentration of the probe spotted on the surface. As demonstrated by the results in Figure 2, the antibody density reaches saturation when sSDNA-PROBE is spotted at $5 \mu \mathrm{M}$. Interestingly, the density decreases when the probe is spotted at $25 \mu \mathrm{M}$ concentration probably due to crowding effect. This effect is more pronounced for anti-CD63 that, being captured more efficiently, reaches a higher surface density at lower probe concentration. Based on capture efficiency, $5 \mu \mathrm{M}$ probes were spotted in all microarray experiments. Moreover, we used ssDNA-antiCD63 for all the experiments as it provides a higher immobilization yield. 
The next step was to demonstrate that DDI antibodies are able to capture EVs from solution. Three silicon chips were functionalized with antiCD63, immobilized both via amine coupling and DDI, and analyzed using SP-IRIS technique. Polyclonal rabbit $\operatorname{lgG}$ spots were the negative control. SP-IRIS chips were incubated with EVs isolated from HEK-293 cell culture media through ultracentrifugation and diluted at a final concentration of $1 * 10^{9}$ particles/mL in PBS (for EVs characterization see Supplementary Informations). The Single-Particle Interferometric Reflectance Imaging Sensor (SP-IRIS) takes advantage of an optical configuration that is similar to the classic IRIS one; in this case, however, the resolution is much higher, due to the presence of a high-magnification objective, and the application is different: the SP-IRIS was indeed conceived to achieve the digital sizing and counting of individual nanoparticles bound to the surface, down to a diameter of $50 \mathrm{~nm}^{31}$. A single wavelength LED is used, which shall be carefully chosen to match the oxide layer thickness in order to achieve the best possible enhancement of the visibility of the nanoparticles. In our case, $55 \mathrm{~nm}-\mathrm{Si} / \mathrm{SiO}_{2}$ chips were used in combination with a near-UV wavelength LED. Scans of the surface along the focal direction $i$ that is, the direction parallel to the objective - are performed, and changes in contrast of a single nanoparticle at distinct focal planes can be directly correlated to its size.

The results (Figure 3) show that, not only DNA directed antiCD63 is able to capture EVs on the surface, but it does this more efficiently than antiCD63 immobilized by a classical procedure, suggesting that the DNA linker confers to this antibody higher affinity towards EVs surface antigen. The increased avidity might result from the flexibility of the spacer between the antibody and the surface that facilitates the interaction of more than one antibody with the same vesicle, making the capture of this bulky target more stable.

Combining the results of the two experiments, it was possible to compare immobilization efficiency of DDI and conventional immobilization as well as their ability to capture EVs (Table 1). It is worth noting that using DDI a sensibly lower amount of antiCD63 was immobilized on the surface, but a much higher number of EVs was captured in comparison with the conventional antibody.

Finally, the release of vesicles catalyzed by DNAse was investigated using SP-IRIS. A SP-IRIS silicon chip was functionalized with DNA directed antiCD63 and subsequently treated with a $250 \mathrm{mKunitz} / \mu \mathrm{L}$ solution of DNAse I for $1 \mathrm{~h}$ at $37^{\circ} \mathrm{C}$. 
Figure 4 shows high resolution images of the same spot at the beginning of the experiment and after treatment with DNAse I. As it can be noted, the spot nearly disappears from the surface after treatment with DNAse I, confirming that a reversible binding of antibodies on microarray surfaces is attained. The use of DNAse I to release EVs may cause the cleavage of DNA exposed on their surface. This could be potentially exploited distinguish DNA sequences are carried into EVs, from those that are linked to their surface. After demonstrating reversible capturing on microarray, we tested this method in preparative scale separation using magnetic beads. A schematic representation of the procedure is described in Figure 5. Magnetic beads, coated with streptavidin, were functionalized with biotinylated ssDNA-PROBE-63 and then with ssDNA-antiCD63. The antibody functionalized beads were incubated with EVs isolated from HEK-293 cell culture media for $2.5 \mathrm{~h}$ at room temperature, and then treated with DNAse I for $1 \mathrm{~h}$ at $37^{\circ} \mathrm{C}$. The same experimental procedure was carried out on beads functionalized with ssDNA-rabbit IgG as negative control. The input material, as well as discarded supernatant and released sample were analyzed by nanoscale flow cytometry (nanoFCM) and spectrophotometry.

NanoFCM is a high-resolution flow cytometry method for analyzing and sorting individual EVs larger than $40 \mathrm{~nm}$. It uses high sensitivity multiparametric scattered light and fluorescence measurements to count and size single nanoparticles ${ }^{32}$. Spectrophotometric analysis, instead, was carried out to assess the overall fluorescence of the sample.

In order to better characterize the performance of the DDI approach, EVs isolated through ultracentrifugation from HEK-293 cell culture media were employed. First, to assess the percentage of CD63 positive EVs, label-free (Fig.6a) and fluorescence analyses were combined. Two aliquots of the same sample were incubated with antiCD63 lgG labeled either with AlexaFluor488 or with phycoerythrin (Fig.6b and 6c, respectively) and analyzed by both, scattering and fluorescence. The two fluorophores gave quite similar results, indicating that around $9 \%$ of EVs in the sample expose CD63 on their surface. 
Then, EVs isolated from HEK cells were stained using the protein-binding dye 5(6)Carboxyfluorescein diacetate $\mathrm{N}$-succinimidyl ester or CFDA-SE (hereinafter referred to as CFSE) following the protocol described in section 2.4.2. CFSE is a dye that has been demonstrated to be optimal for EV staining, since it produces no aggregates and artifacts that alter the nanoFCM analysis ${ }^{32}$. Using this approach, $70 \%$ of the particles were successfully stained with CFSE (Fig.7).

Magnetic beads, functionalized with ssDNA-antiCD63 or ssDNA-rabbit IgG, were incubated with CFSE-stained EVs for $2.5 \mathrm{~h}$ at room temperature. After incubation the supernatant was recovered and analyzed with both nanoFCM and spectrophotometer.

Figure 8 shows the percentage of fluorescently labeled EVs captured by the beads (the data are obtained by subtracting the readout after incubation to that of the initial solution) for the two detection methods. Both analyses show the same trend, with more particles captured by beads functionalized with EV-specific IgG than by the negative control. The discrepancies observed in the two analysis methods depend on the difference between the principle used to quantify EVs. While nanoFCM counts only signals associated to nanoparticles, the spectrophotometer reads the total signal, including background fluorescence. Both methods provide only a rough estimation of the capturing efficiency. The percentage of captured vesicles is higher than expected considering that CD63+ EVs are only $9 \%$ of the whole vesicle population. There might be EVs non-specifically bound to the beads, which are washed away only during subsequent washing steps.

In order to perform enzymatic release of captured EVs, the magnetic beads, incubated with DNAse I $250 \mathrm{mKunitz} / \mu \mathrm{L}$ in release buffer for $1 \mathrm{~h}$ at $37^{\circ} \mathrm{C}$, were separated using a magnetic stand and the supernatant was recovered and analyzed. The results of NanoFCM analysis shown in Figure 9 revealed that around $6 \%$ of input vesicles were released from the beads (with an overall yield of $66 \%$ taking into account CD63+ subpopulation) while no detectable particles were recovered from the negative control. The experiment demonstrates that the method herein proposed captures reversibly intact EVs since only nanoparticles that are surrounded by an intact membrane are revealed both by scattering light and fluorescence emission by nanoFCM. 
Once demonstrated the DDI approach works in preparative separation, the system was tested for EV-capture from human blood plasma, following the same experimental procedure developed for HEK cell-derived EVs.

This separation approach was also compared with two different broadly used EV separation methods. Aliquots of $\mathrm{SEV}$ s from the same plasma sample were purified using either conventional immunocapture, which uses magnetic particles covalently functionalized with the same clone of antiCD63 antibody, or ultracentrifugation.

The samples, separated by the three methods, were characterized by Nanoparticle Tracking Analysis (NTA); their size distributions are reported in Figure 10. Only the sample purified by immunoaffinity with DNA directed immobilized antibodies has the typical size distribution of SEVs ranging between 50 and $200 \mathrm{~nm}$ while the profile of the other two samples looks different and shows the presence of large particle that are clearly the result of aggregation of small vesicles induced by the harsh treatment (400-500 nm). These aggregates result from the separation proc ess as in the prepurified sample large EVs have been removed by filtration on a $200 \mathrm{~nm}$ filter. The profile of the sample that was immunocaptured by conventional approach was somehow expected, since the release buffer contains a detergent that causes membrane degradation. Less obvious was the profile of the sample obtained by ultracentrifugation that, in principle, should isolate intact vesicles.

In Figure 11 the NTA profile of nanoparticles released from magnetic beads with DNAse I (orange curve) was compared with that of the buffer containing only the enzyme (blue curve). It is evident from the traces of Figure 11 that the particles in the 75-200 $\mathrm{nm}$ range come from the beads, since a significant percentage of bigger particles $(200-300 \mathrm{~nm})$ is present in the enzyme buffer.

To confirm that the sample solution, coming from DDI approach, contained nanoparticles with size and shape corresponding to sEVs a Trasmission Electron Microscopy (TEM) analysis on fresh material was carried out. In Fig.12a single vesicles and aggregates of EVs can be noted, as well as lighter and cloudy regions that might be attributed to protein aggregates (DNAse I and antiCD63 released from magnetic beads). In Fig.12b an enlargement of a single vesicle of approximately 60 $\mathrm{nm}$ in diameter is shown.

Finally, in addition to TEM, released vesicles were characterized using SP-IRIS. Commercial silicon chips, functionalized with antibodies directed against tetraspanins CD9, CD63 and CD81 and a mouse IgG as negative control 
(ExoView ${ }^{\mathrm{TM}}$ Tetraspanin Kit, Nanoview Biosciences, USA) were incubated with sEVs purified on DDI magnetic beads, while control chips were incubated with DNAse I buffer. The results are shown in Fig.13. The DNAse I buffer does not contain particles that can be captured by the antibodies on the chip. On the contrary, a significant number of nanoparticles was captured on the anti-CD9 spot incubated with purified sEVs. The low number of particles captured on CD81 spots can be explained by a low co-expression of CD63 and CD81 in this preparation while the low level of particles captured on antiCD63 spots might depend on the fact that most of the CD63 molecules on the surface are masked by the antibody used for their capture during the separation step. The antibody released by cleavage of the DNA linker could have interacted with the antigen, hampering the capture on the microarray surface. In fact, the EVs released can be considered immuno-complexes that might have significant biological effects such as activation of complement or interaction with cells expressing Fcy receptor. Even though this drawback obstacles EVs use in therapeutics applications, the method is still highly compatible with their use as biomarkers in clinical applications.

\section{Acknowledgements}

This work was supported by European Union Horizon 2020 under Grant 766466: INDEX, Integrated Nanoparticle isolation and Detection system for complete on-chip analysis of Exosomes.

\section{Conflicts of interest}

The authors declare the following competing financial interest: Marcella Chiari has filed an Italian Patent Application (102019000018239) on the bases of these data.

\section{References}

1 Théry C, Amigorena S, Raposo G, Clayton A. Isolation and Characterization of Exosomes from Cell Culture Supernatants and Biological Fluids. Current Protocols in Cell Biology 2006;30:3.22.1-3.22.29.

2 Tauro BJ, Greening DW, Mathias RA, Ji H, Mathivanan S, Scott AM, Simpson 
RJ. Comparison Of Ultracentrifugation, Density Gradient Separation, And Immunoaffinity Capture Methods For Isolating Human Colon Cancer Cell Line LIM1863-Derived Exosomes. Methods 2012;56:293ï 304.

3 Nordin JZ, Lee $Y$, Vader $P$, Mäger I, Johansson HJ, Heusermann W, Wiklander OP, Hällbrink M, Seow Y, Bultema JJ, Gilthorpe J, Davies T, Fairchild PJ, Gabrielsson S, Meisner-Kober NC, Lehtiö J, Smith Cl, Wood MJ, El Andaloussi S. Ultrafiltration With Size-Exclusion Liquid Chromatography For High Yield Isolation Of Extracellular Vesicles Preserving Intact Biophysical And Functional Properties. Nanomedicine: Nanotechnology, Biology and Medicine 2015;11:879ї 883.

4 Böing AN, van der Pol E, Grootemaat AE, Coumans FAW, Sturk A, Nieuwland R. Single-Step Isolation Of Extracellular Vesicles By Size-Exclusion Chromatography. Journal of extracellular vesicles 2014;3.

5 Yamamoto KR, Alberts BM, Benzinger R, Lawhorne L, Treiber G. Rapid Bacteriophage Sedimentation In The Presence Of Polyethylene Glycol And Its Application To Large-Scale Virus Purification. Virology 1970;40:734ї 744.

6 Adams A. Concentration of Epstein-Barr Virus from Cell Culture Fluids with Polyethylene Glycol. Journal of General Virology 1973;20:391ї 394.

7 Ghosh A, Davey M, Chute IC, Griffiths SG, Lewis S, Chacko S, Barnett D, Crapoulet N, Fournier S, Joy A, Caissie MC, Ferguson AD, Daigle M, Meli MV, Lewis SM, Ouellette RJ. Rapid Isolation of Extracellular Vesicles from Cell Culture and Biological Fluids Using a Synthetic Peptide with Specific Affinity for Heat Shock Proteins. PLOS ONE 2014;9:e110443.

8 Wang K, Zhang S, Weber J, Baxter D, Galas DJ. Export Of Micrornas And Microrna-Protective Protein By Mammalian Cells. Nucleic Acids Research 2010;38:7248ї 7259 .

9 Jørgensen $M$, Bæk R, Pedersen S, Søndergaard EKL, Kristensen SR, Varming K. Extracellular Vesicle (EV) Array: Microarray Capturing Of Exosomes And Other Extracellular Vesicles For Multiplexed Phenotyping. 
Journal of Extracellular Vesicles 2013;2:20920.

10 Théry C, Witwer KW, Aikawa E, Jose Alcaraz M, Anderson JD, Andriantsitohaina $R$, et al. Journal of Extracellular Vesicles Minimal information for studies of extracellular vesicles 2018 (MISEV2018): a position statement of the International Society for Extracellular Vesicles and update of the MISEV2014 guidelines. Journal of Extracellular Vesicles 2018;7:1535750.

11 Zhang Y-F, Shi J-B, Li C. Small Extracellular Vesicle Loading Systems In Cancer Therapy: Current Status And The Way Forward. Cytotherapy 2019;21(11):1122-1136.

12 El-Sayed IY, Mikuz G, Giulietti M, Santoni M, Cimadamore A, Carrozza F, Piva F, Cheng L, Lopez-Beltran A, Scarpelli M, Battelli N, Montironi R. Exploring Small Extracellular Vesicles for Precision Medicine in Prostate Cancer. Frontiers in Oncology 2018;8:221.

13 Min L, Zhu S, Chen L, Liu X, Wei R, Zhao L, Yang Y, Zhang Z, Kong G, Li P, Zhang S. Evaluation Of Circulating Small Extracellular Vesicles Derived Mirnas As Biomarkers Of Early Colon Cancer: A Comparison With Plasma Total Mirnas. Journal of Extracellular Vesicles 2019;8:1643670.

14 Niemeyer CM, Boldt L, Ceyhan B, Blohm D. DNA-Directed Immobilization: Efficient, Reversible, and Site-Selective Surface Binding of Proteins by Means of Covalent DNAï Streptavidin Conjugates. Analytical Biochemistry 1999;268:54ї 63.

15 Wacker R, Niemeyer CM. DDI- $E$ FIA-A Readily Configurable MicroarrayFluorescence Immunoassay Based on DNA-Directed Immobilization of Proteins. ChemBioChem 2004;5:453ï 459.

16 Seymour E, Daaboul GG, Zhang X, Scherr SM, Ünlü NL, Connor JH, Ünlü SM. DNA-Directed Antibody Immobilization for Enhanced Detection of Single Viral Pathogens. Analytical Chemistry 2015;87:10505ï 10512.

17 Trads JB, Tørring T, Gothelf K V. Site-Selective Conjugation of Native Proteins with DNA. Accounts of Chemical Research 2017;50:1367ï 1374. 
18 Sano T, Smith C, Cantor C. Immuno-PCR: Very Sensitive Antigen Detection By Means Of Specific Antibody-DNA Conjugates. Science 1992;258:120ï 122.

19 Agasti SS, Liong M, Peterson VM, Lee H, Weissleder R. Photocleavable DNA Barcodeï Antibody Conjugates Allow Sensitive And Multiplexed Protein Analysis In Single Cells. Journal of the American Chemical Society 2012;134:18499ї 18502.

20 Agard NJ, Prescher JA, Bertozzi CR. A Strain-Promoted [3+2] Azideī Alkyne Cycloaddition for Covalent Modification of Biomolecules in Living Systems. Journal of the American Chemical Society 2004;126:15046ï 15047.

21 Sambrook J, Russell DW. Molecular Cloning : A Laboratory Manual. Cold Spring Harbor Laboratory Press; 2001.

22 EV-TRACK Consorptium, Van Deun J et al. EV-TRACK: Transparent Reporting And Centralizing Knowledge In Extracellular Vesicle Research. Nature Methods 2017;14(3):228-232.

23 Needham JW, Ünlü NL, Yurdakul C, Ünlü MS. Interferometric Reflectance Imaging Sensor (IRIS) for Molecular Kinetics with a Low-Cost, Disposable Fluidic Cartridge. Methods in molecular biology 2019;2027:15ï 28.

24 Daaboul GG, Vedula RS, Ahn S, Lopez CA, Reddington A, Ozkumur E, Ünlü MS. LED-Based Interferometric Reflectance Imaging Sensor For Quantitative Dynamic Monitoring Of Biomolecular Interactions. Biosensors and Bioelectronics 2011;26:2221ï 2227.

25 Sevenler D, Selim Ünlü M. Numerical Techniques For High-Throughput Reflectance Interference Biosensing. Journal of Modern Optics 2016;63:1115ї 1120.

26 Pirri G, Damin F, Chiari M, Bontempi E, Depero LE. Characterization of A Polymeric Adsorbed Coating for DNA Microarray Glass Slides. Analytical Chemistry 2004;76:1352ï 1358.

27 Zhu S, Ma L, Wang S, Chen C, Zhang W, Yang L, Hang W, Nolan JP, Wu L, Yan X. Light-Scattering Detection below the Level of Single Fluorescent 
Molecules for High-Resolution Characterization of Functional Nanoparticles. ACS Nano 2014;8:10998-11006.

28 Tian Y, Ma L, Gong M, Su G, Zhu S, Zhang W, Wang S, Li Z, Chen C, Li L, Wu L, Yan X. Protein Profiling and Sizing of Extracellular Vesicles from Colorectal Cancer Patients via Flow Cytometry. ACS Nano 2018;12:671ї 680.

29 Tian Y, Gong M, Hu Y, Liu H, Zhang W, Zhang M, Hu X, Aubert D, Zhu S, Wu L, Yan X. Quality And Efficiency Assessment Of Six Extracellular Vesicle Isolation Methods By Nano-Flow Cytometry. Journal of Extracellular Vesicles 2020;9:1697028.

30 Konoshenko MY, Lekchnov EA, Vlassov A V, Laktionov PP. Isolation of Extracellular Vesicles: General Methodologies and Latest Trends. Biomed Research International 2018:8545347.

31 Daaboul GG, Lopez CA, Chinnala J, Goldberg BB, Connor JH, Ünlü MS. Digital Sensing and Sizing of Vesicular Stomatitis Virus Pseudotypes in Complex Media: A Model for Ebola and Marburg Detection. ACS Nano 2014;8:6047ї 6055.

32 Morales-Kastresana A, Telford B, Musich TA, McKinnon K, Clayborne C, Braig Z, Rosner A, Demberg T, Watson DC, Karpova TS, Freeman GJ, DeKruyff $\mathrm{RH}$, Pavlakis GN, Terabe M, Robert-Guroff M, Berzofsky JA, Jones JC. Labeling Extracellular Vesicles For Nanoscale Flow Cytometry. Scientific Reports 2017;7:1ї 10. 


\begin{tabular}{|c|c|c|}
\hline IMMOBILIZATION STRATEGY & $\begin{array}{c}\text { ANTIBODY } \\
\text { DENSITY } \\
\left(\mathbf{p g} / \mathbf{m m}^{2}\right)\end{array}$ & $\begin{array}{c}\text { CAPTURED EVs } \\
\left(\mathbf{k P a r t i c l e s} / \mathbf{m m}^{2}\right)\end{array}$ \\
\hline $\begin{array}{c}\text { Amine Coupling } \mathbf{( 2} \mathbf{~ m g} / \mathbf{m L}) \\
\text { DNA-Directed Immobilization } \\
\mathbf{( 5} \boldsymbol{\mu M})\end{array}$ & $1558 \pm 5$ & $42.6 \pm 3.6$ \\
\hline
\end{tabular}

Tab.1

Table 1. Comparison between immobilization densities and EV-capture efficiencies for antiCD63 immobilized on the surface through amine coupling and DNA-directed immobilization (data come from experiments described in sections 2.3.2 and 2.3.3). 


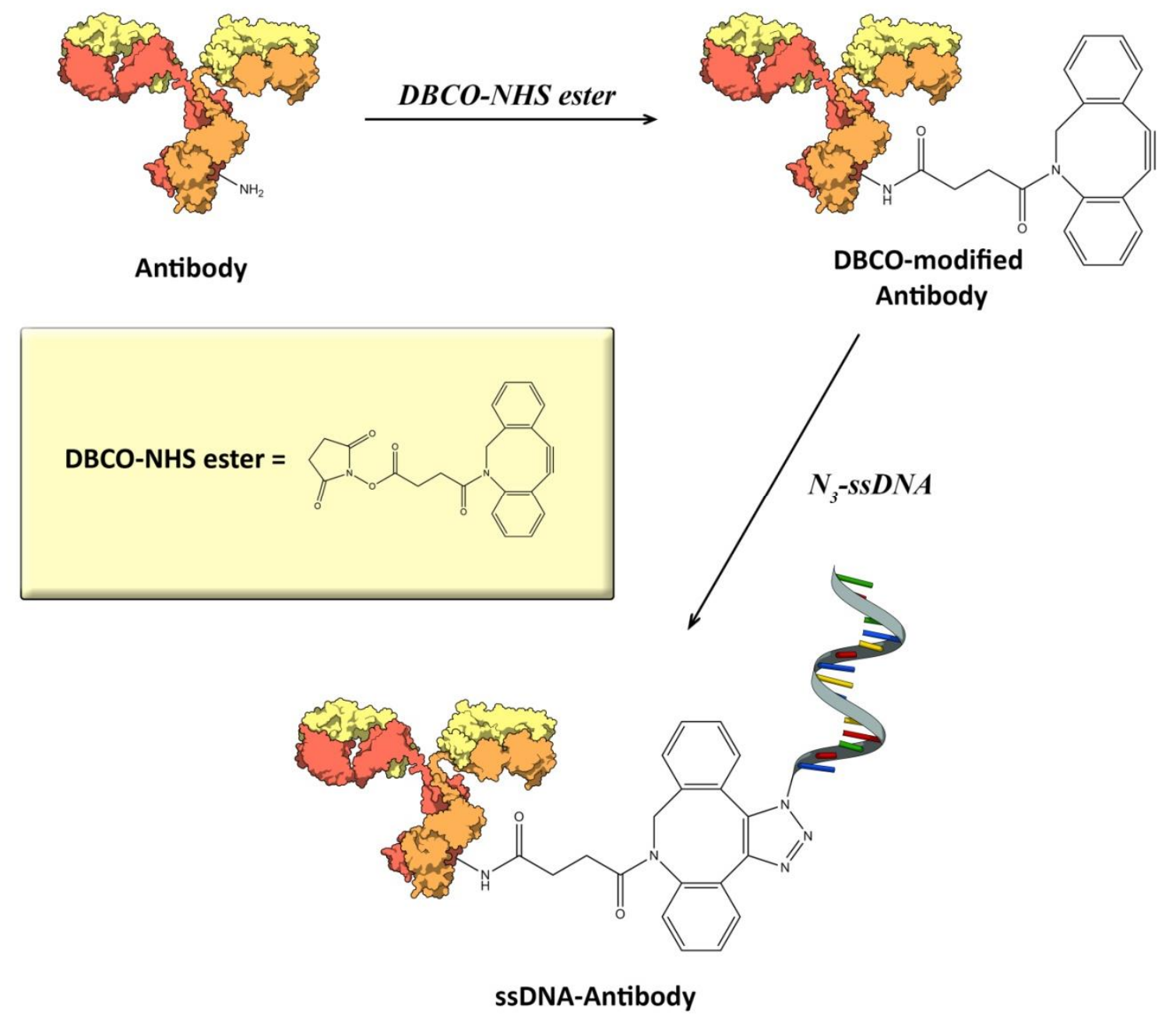

Fig.1 
a)

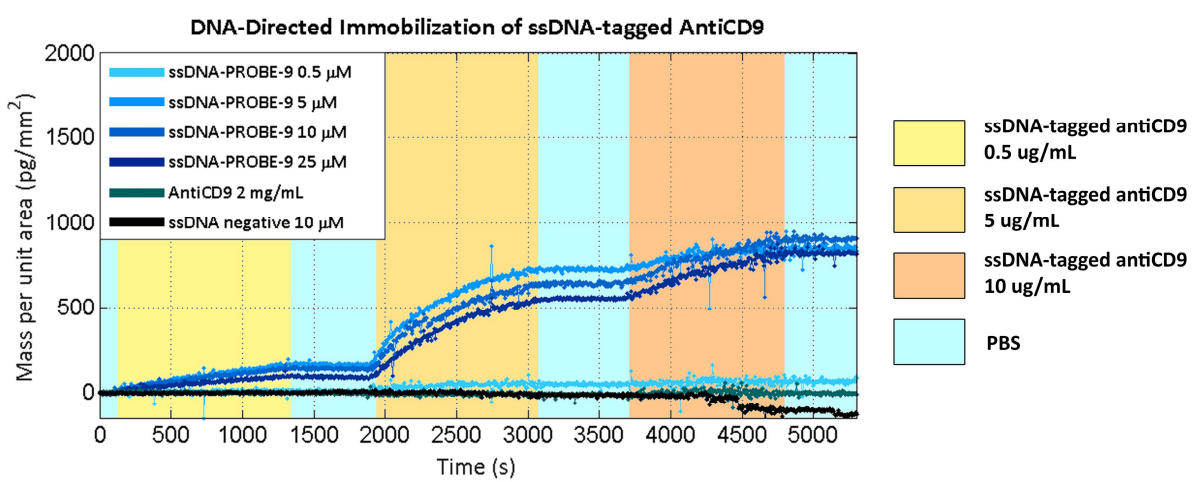

b)

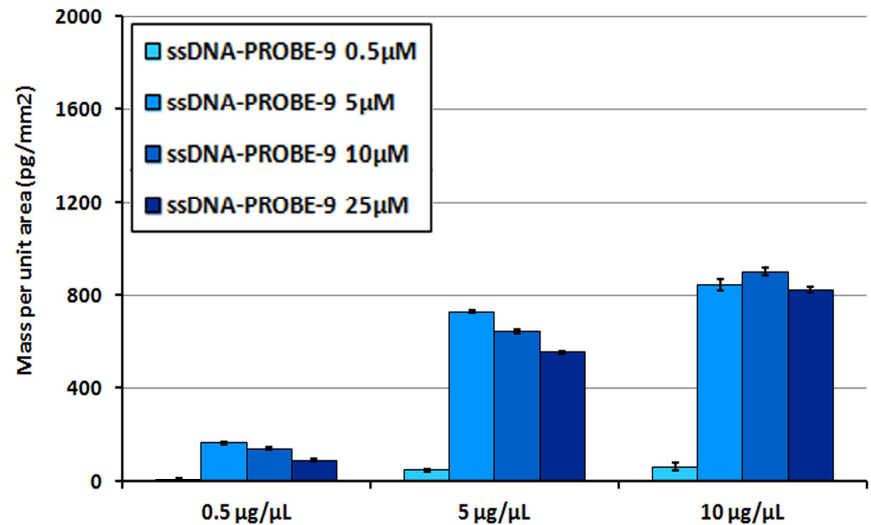

c)

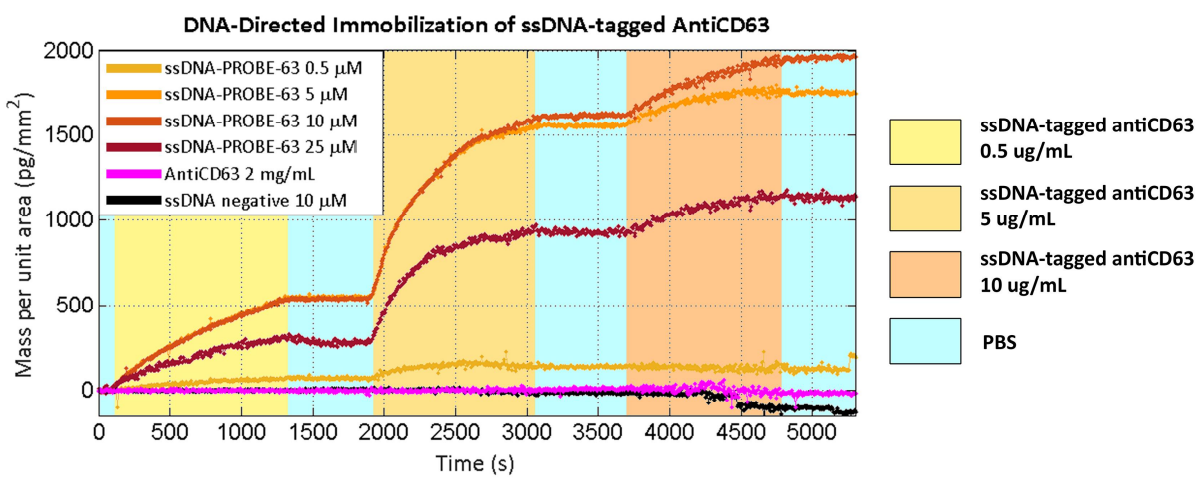

d)

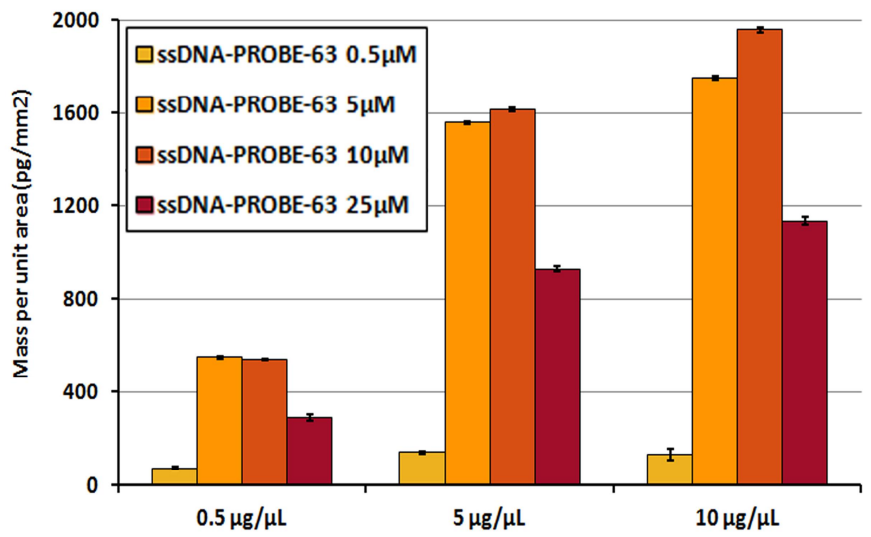


Fig.2

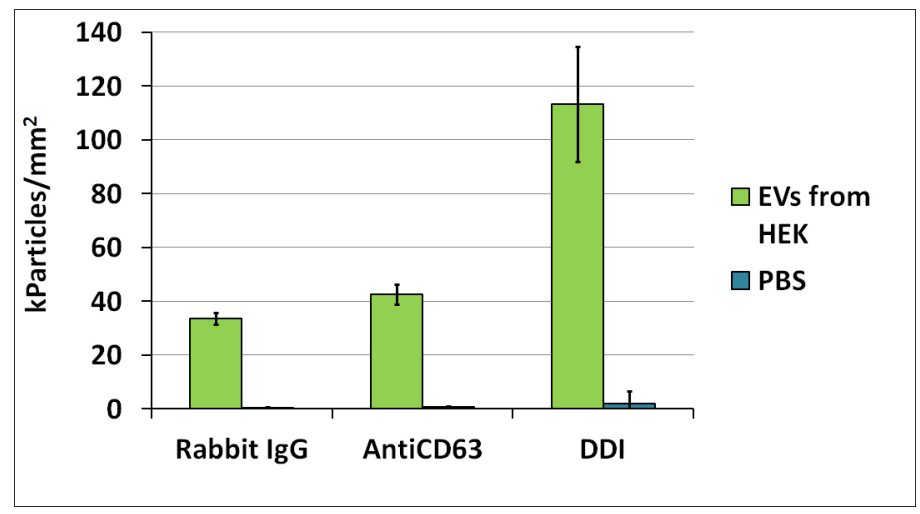

Fig.3

a)

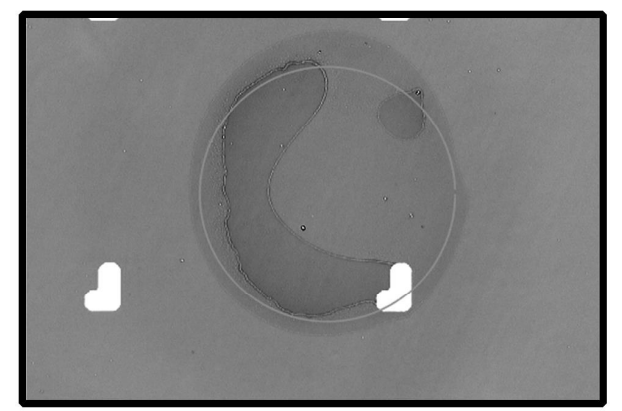

b)

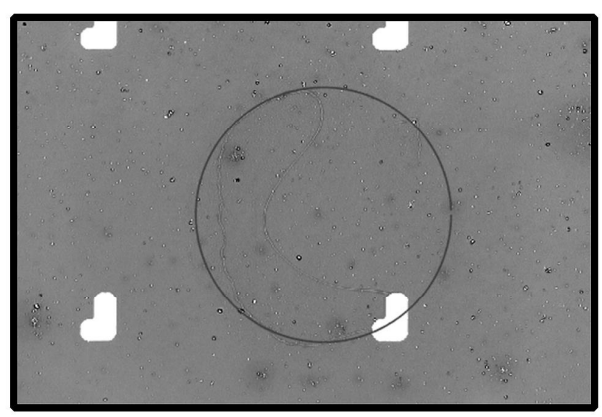

Fig.4 


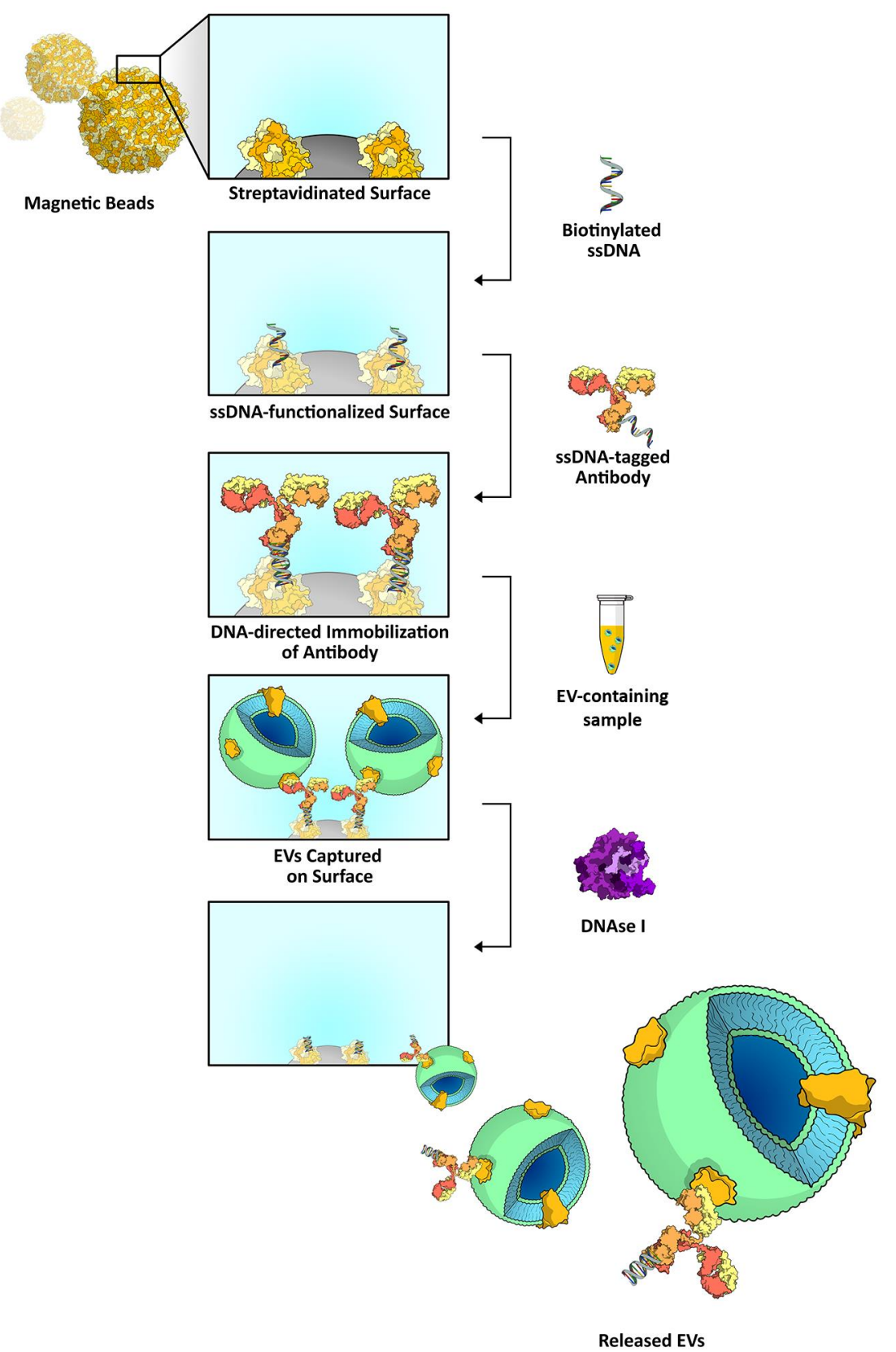

Fig.5 
a)

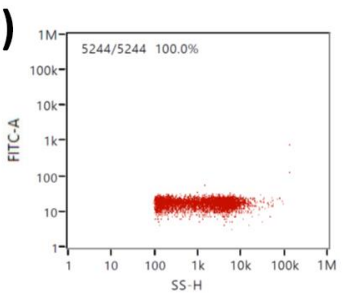

d)

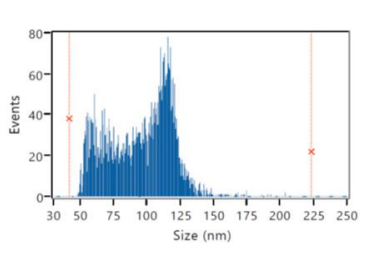

b)

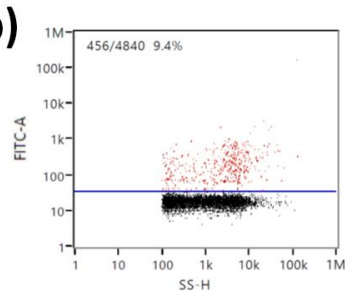

e)

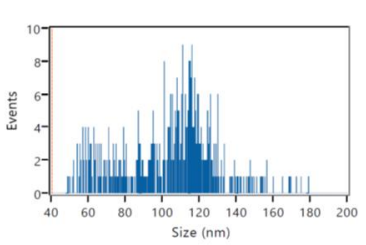

c)

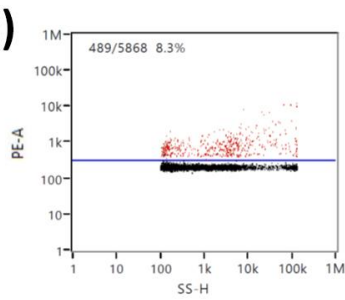

f)

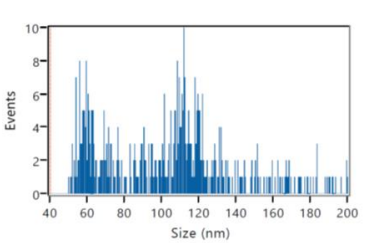

Fig.6

a)

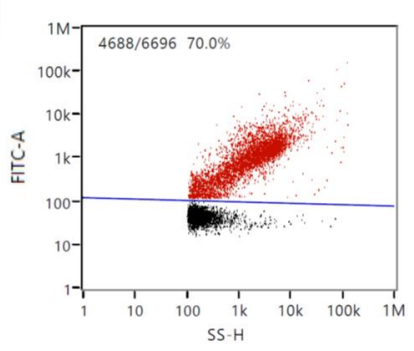

b)

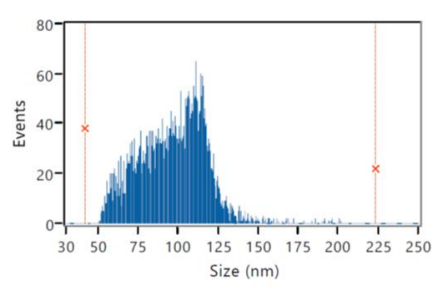

Fig.7

a)

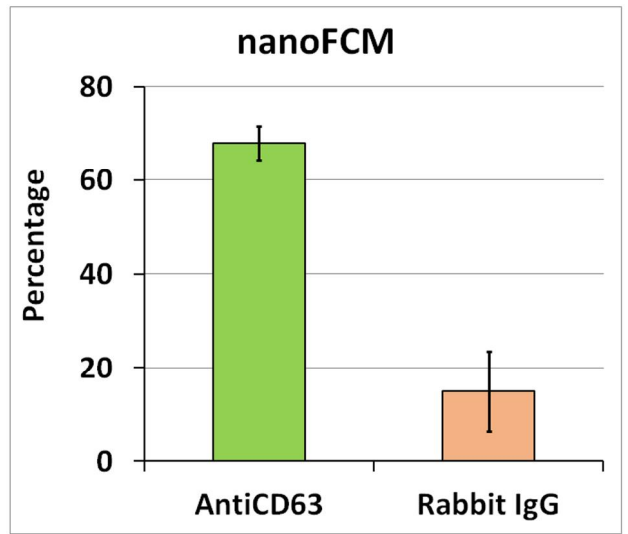

b)

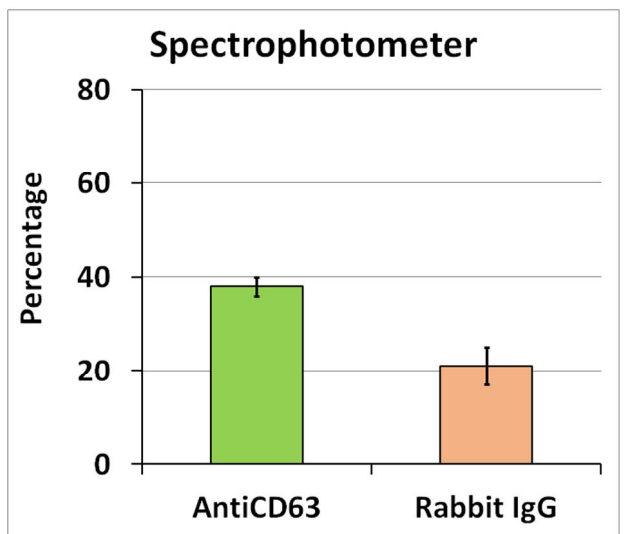

Fig.8 
a)

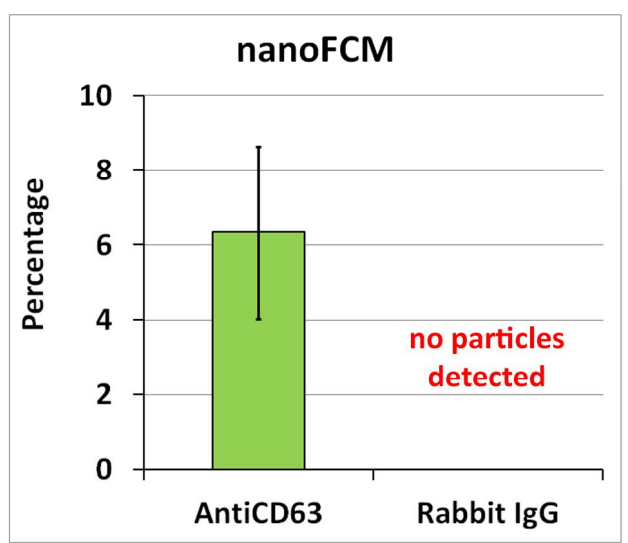

b)

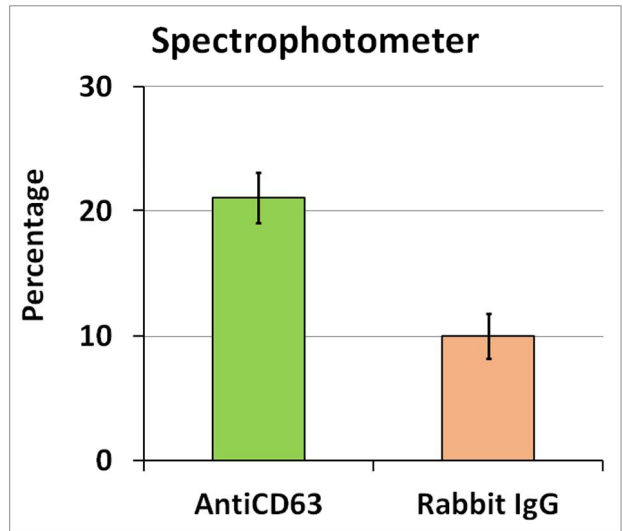

Fig.9

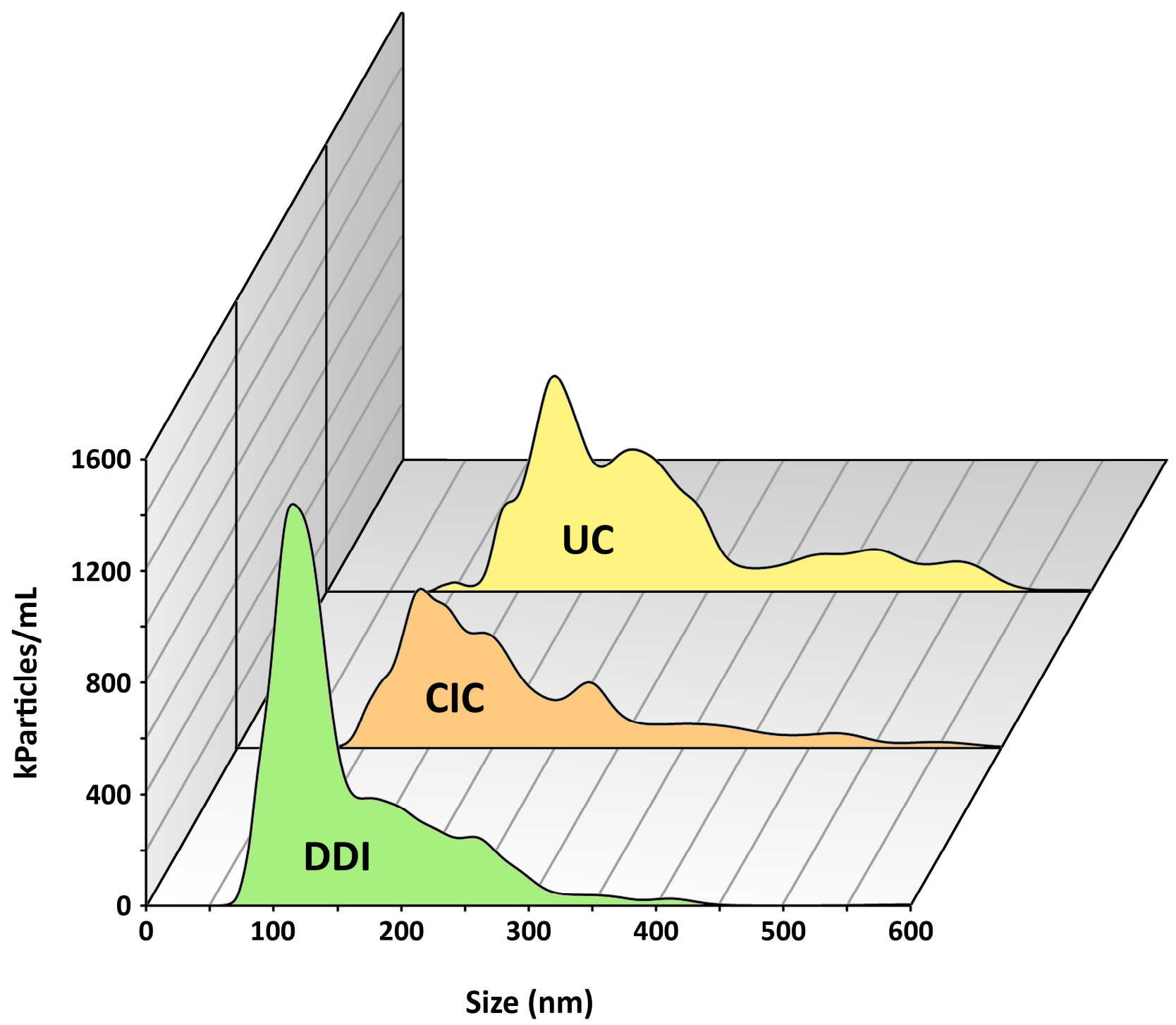


Fig.10

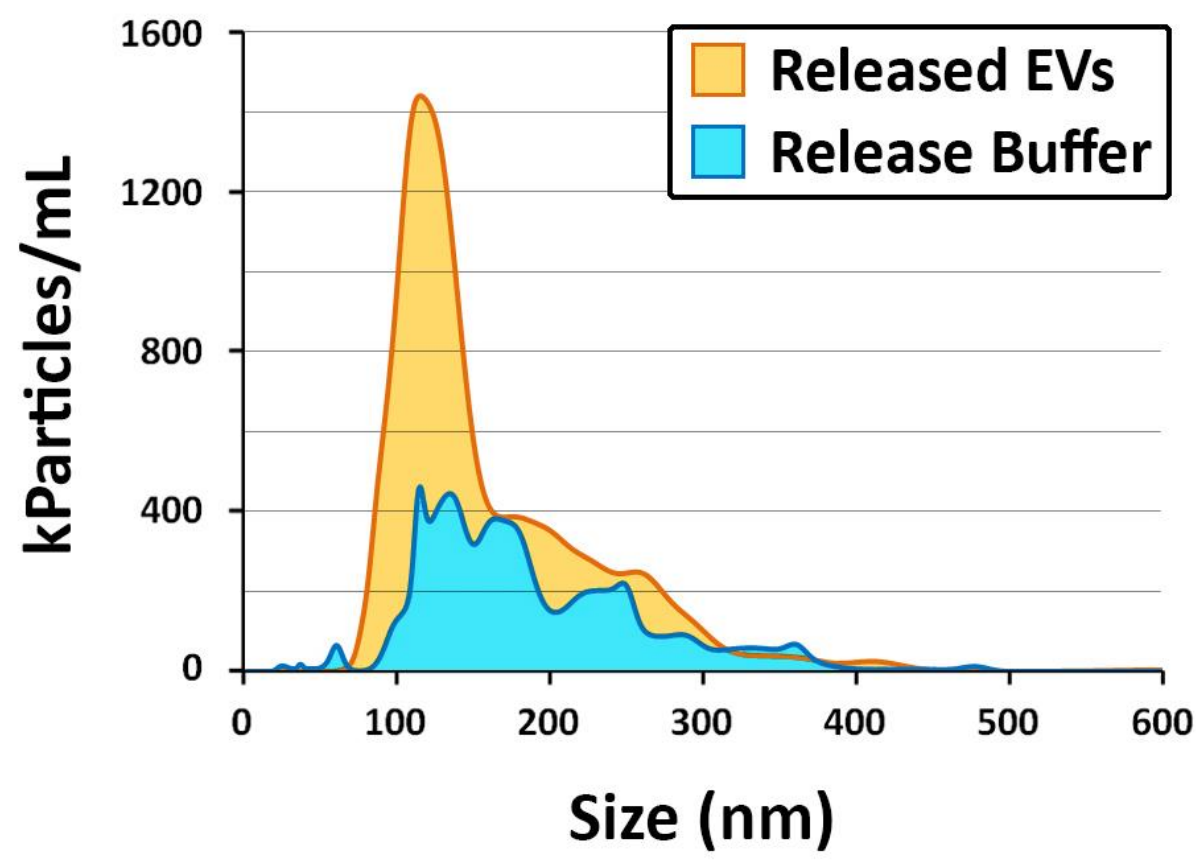

Fig.11

a)

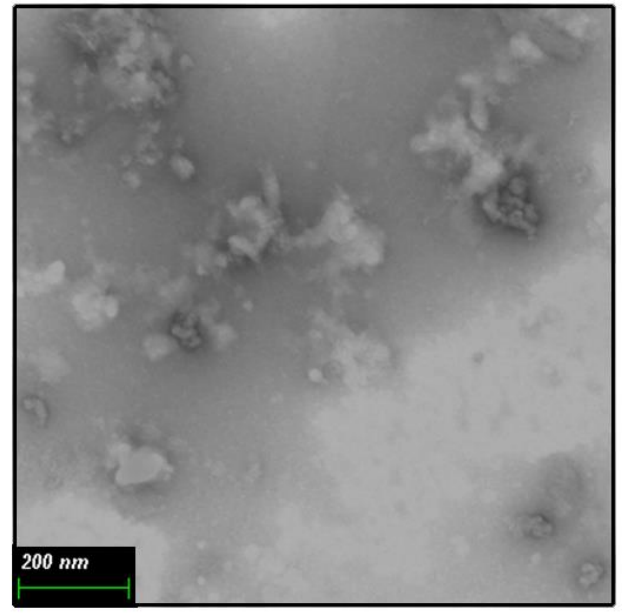

b)

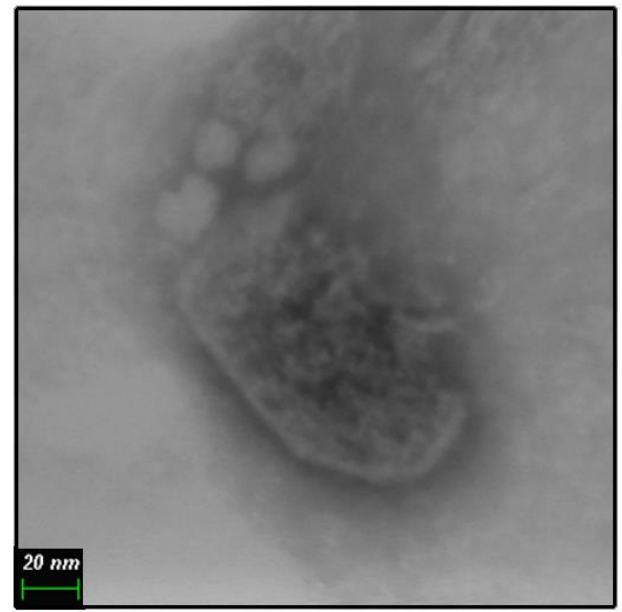

Fig.12 
a)

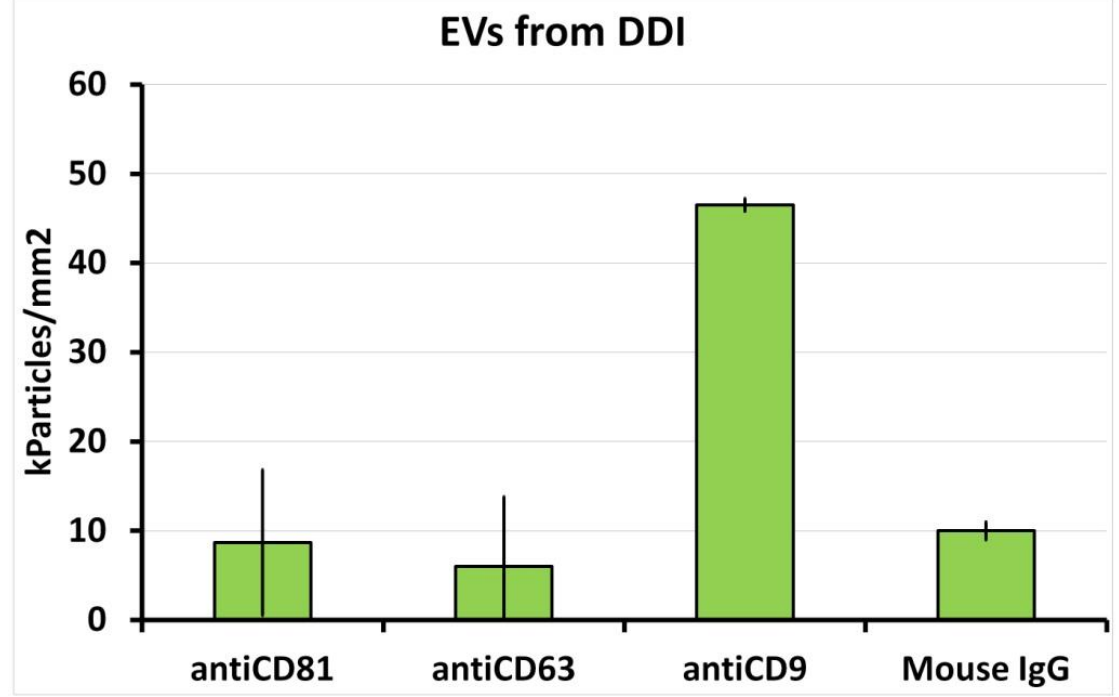

b)

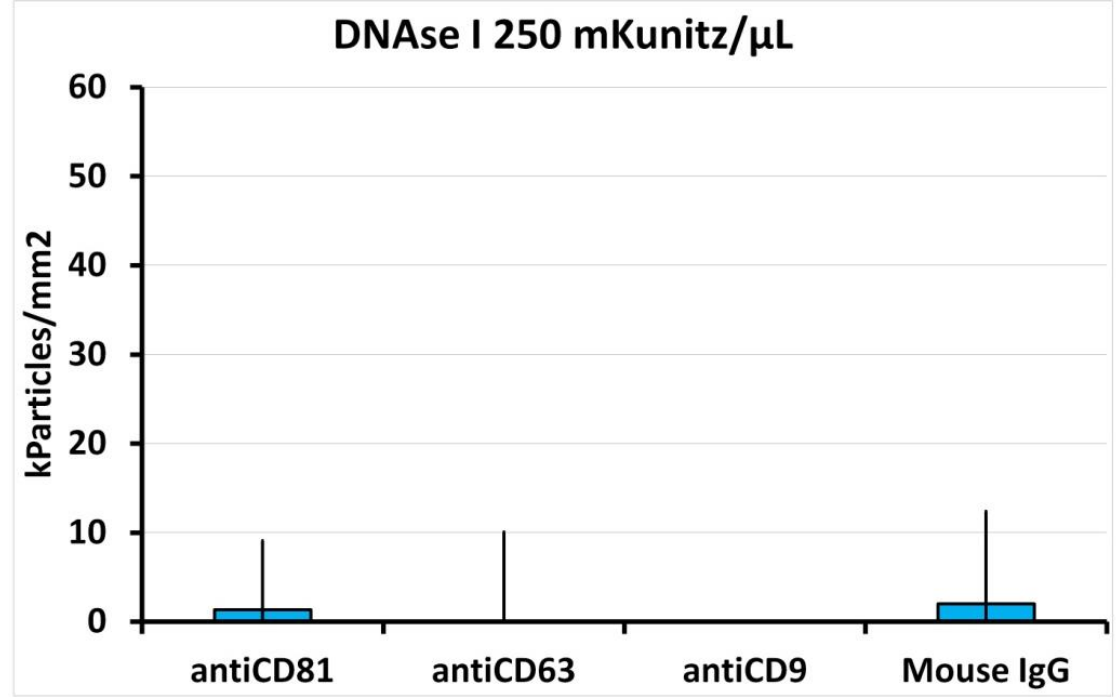

Fig.13

Figure 1. Schematic representation of the synthetic route to obtain ssDNA-tagged antibody.

Figure 2. Real-time IRIS analysis of mass accumulation of DNA-directed antibodies: $a$ and c) mass accumulation over time on spots of SSDNA-antiCD9 and SSDNAanti-CD63 spotted at 0.5, 5, 10 and $25 \mu \mathrm{M}$ concentration respectively, b) and d). Antibody density at equilibrium from graphs a) and c) respectively. Average values from three experiments. 
Figure 3. Average densities of nanoparticles captured on polyclonal rabbit lgG and antiCD63 immobilized via amine coupling and antiCD63 DNA-directed on $5 \mu \mathrm{M}$ sSDNA-PROBE-63 (labeled as DDI) after incubation with EVs isolated from HEK cell culture media $\left(1 * 10^{9}\right.$ particles $\left./ \mathrm{mL}\right)$ or PBS only. Average values from three independent experiments.

Figure 4. SP-IRIS images of a single spot of DNA-directed antiCD63 before (a) and after treatment with DNAse I (b).

Figure 5. Schematic representation of DDI-based separation of sEVs on magnetic beads.

Figure 6. Nanoscale Flow Cytometry analysis of EVs isolated from HEK cell culture media using ultracentrifugation. Data for unstained vesicles, as well as EVs labeled with AlexaFluor488 and phycoerithryn conjugated antiCD63 ( $a, b$ and $c$, respectively). The size distribution of the same samples is shown in the bottom of the image ( $d$, e and $f$, respectively).

Figure 7. Nanoscale Flow Cytometry analysis of EVs stained using CFSE (a) and their size distribution (b).

Figure 8. Analysis of particles captured after immuno precipitation on DDI functionalized magnetic beads using both nanoscale Flow Cytometry (a) and spectrophotometric detection (b).

Figure 9. Analysis of particles released from magnetic beads by treatment with DNAse I using both nanoscale Flow Cytometry (a) and spectrophotometric detection (b).

Figure 10. Nanoparticle Tracking Analysis of samples recovered using DDI approach, covalently functionalized magnetic beads (CIC) and ultracentrifugation (UC).

Figure 11: Nanoparticle Tracking Analysis of sample recovered using DDI approach (orange curve) and DNAse I containing buffer (blue curve). 
Figure 12: Transmission electron microscopy (TEM) analysis of sample recovered with DDI approach. Wide field image of negatively stained sEVs and lighter cloudy regions due to protein aggregates, bar indicates $200 \mathrm{~nm}$ (a). Close up image of a single released $S E V$, bar indicates $20 \mathrm{~nm}$ (b).

Figure 13 : Particles captured on a microarray chip, detected using SP-IRIS. a) particles captured from EV containing sample. b) particles captured using DNAse I buffer. 
Separation of extracellular vesicles by DNA-directed immu... (3.08 MiB) view on ChemRxiv • download file 


\section{Separation of extracellular vesicles by DNA- directed immunocapturing followed by enzymatic release}

Dario Brambilla ${ }^{1 *}$, Laura Sola ${ }^{1}$, Elisa Chiodi ${ }^{1}$, Natasa Zarovni ${ }^{2}$, Diogo Fortunato ${ }^{2}$, Mattia Criscuoli ${ }^{2}$, Vincenza Dolo ${ }^{3}$, Ilaria Giusti ${ }^{3}$, Valentina Murdica ${ }^{4}$, Riccardo Vago ${ }^{4,5}$, Marcella Chiari $^{1}$

1) Institute of Chemical Science and Technology, National Research Council of Italy (CNR-SCITEC), Milan, Italy

2) Exosomics Siena S.p.A, Siena, Italy

3) Department of Life, Health and Environmental Sciences, University of L'Aquila, L'Aquila, Italy

4) Urological Research Institute, Division of Experimental Oncology, IRCCS San Raffaele Scientific Institute, Milan, Italy

5) Università Vita-Salute San Raffaele, Milan, Italy

*corresponding author: dario.brambilla@icrm.cnr.it 


\section{Materials}

Phosphate buffer saline tablets (PBS), Tris, 37\% chloric acid ( $\mathrm{HCl}$ ), sodium chloride $(\mathrm{NaCl})$, Tween 20, glycerol, sodium dodecyl sulfate (SDS) and bromophenol blue were purchased from Sigma Aldrich (St. Louis, MO, USA). Oligonucleotides were synthesized by MWG-Biotech AG (Ebevsberg, Germany).

\section{Oligonucleotide sequences :}

- ssDNA-TAG-63: 50̂AAAAAGCCTACGAATGAACAGACTG-30̂

- ssDNA-PROBE-63: 50̂ATATGTACCCACCGCATTCTCAGTCTGTTCATTCGTAGGC-3ô

- ssDNA-TAG-9: 5AAAAAATACAGAGTTAGTCGCAGTGG-3'

- SSDNA-PROBE-9: 5ÔATCCGACCTTGACATCTCTACCACTGCGACTAACTCTGTA-3'

- COCU8 : 5ôGCCCACCTATAAGGTAAAAGTGA-3ô

\section{Characterization of EVs isolated from HEK-293 cell culture media by ultracentrifugation}

3.1 Nanoparticle Tracking Analysis: sample was diluted 1:1000 in PBS and analyzed using Nanosight NS300 (Malvern Panalytical, Malvern, UK). The ideal concentration was assessed by pre-testing the optimal particle per frame value (20-100 particles per frame). Videos were analyzed by the in-build NanoSight Software NTA 3.2 Dev Build 3.2.16. The Camera type, Camera level, and Detect Treshold were sCMOS, 13 and 5, respectively. The number of completed tracks in NTA measurments was 5 (a 60 seconds movie was registered for each measurement).

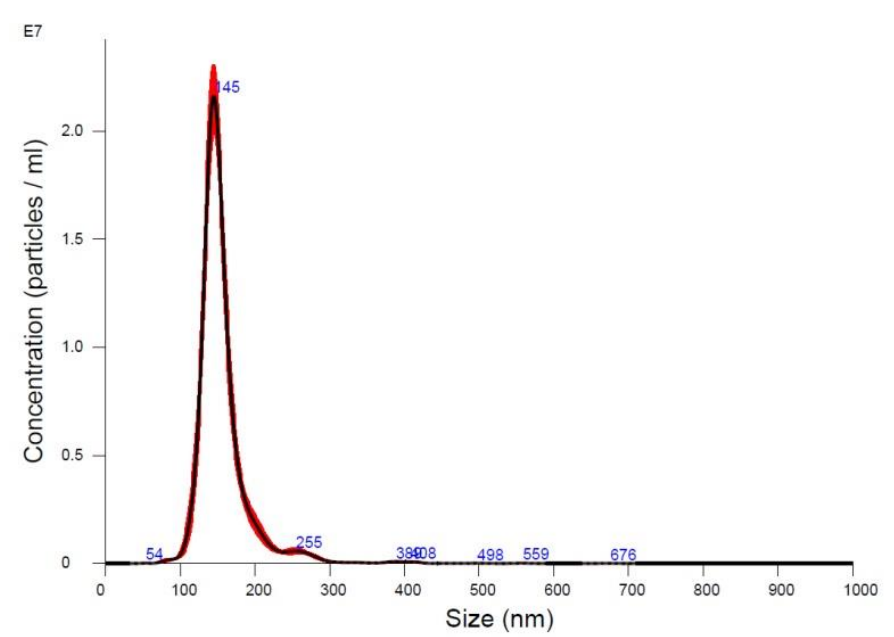


Figure S1. Nanoparticle Tracking Analysis of EVs isolated from HEK-293 cell culture media by ultracentrifugation.

3.2 Western Blot Analysis: Protein content was determined using protein assay kit (BioRad, CA, USA). Bovine serum albumin (BSA) was used as standard. For tetraspanin detection, sample was lysed in non reducing sample buffer $(62.5 \mathrm{mM}$ Trisï $\mathrm{HCl} \mathrm{pH} 6.8$, $10 \%$ glycerol, $2 \%$ SDS, and $0.04 \%$ bromophenol blue) and boiled for $5 \mathrm{~min}$ at $95^{\circ} \mathrm{C}$. Then, $15 \mu \mathrm{g}$ of proteins were loaded on $12 \%$ SDS-PAGE gel. For the detection of other proteins, sample was lysed in reducing sample buffer $(62.5 \mathrm{mM}$ Trisï $\mathrm{HCl} \mathrm{pH} \mathrm{6.8,10 \%} \mathrm{glycerol,} 2 \%$ SDS, $1.25 \%$ 2-mercaptoethanol and $0.01 \%$ bromophenol blue) and boiled for $5 \mathrm{~min}$ at $95^{\circ} \mathrm{C}$. Then, $24 \mu \mathrm{g}$ of proteins were loaded on 12\% SDS-PAGE gel. After protein separation, gels were electro-transferred onto a nitrocellulose membrane. Nonspecific binding sites were blocked with $5 \%(\mathrm{w} / \mathrm{v})$ skimmed milk in T-TBS $(150 \mathrm{mM} \mathrm{NaCl}, 20 \mathrm{mM}$

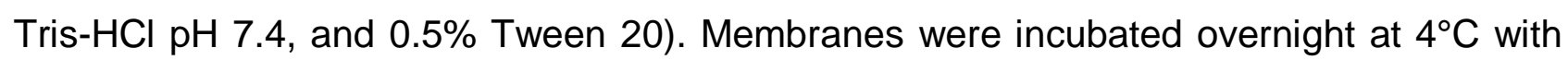
the following antibodies: anti-CD63 (1:1000, \#556019, BD Pharmingen, CA, USA), antiCD81(1:5000, \#555675; BD Pharmingen), anti-Alix (1:500, \#sc-271975, Santa Cruz, CA, USA) and anti-Calnexin (1:1000, \#C7617, Sigma-Aldrich, MO, USA). After several washes in T-TBS, membranes were incubated with goat anti-mouse IgG conjugated to horseradish peroxidase (1:5000, \#170-6516, BioRad Laboratories Inc., CA, USA) for $45 \mathrm{~min}$. Positive immunoreactive bands were detected by the enhanced chemiluminescence method (Immobilon ${ }^{\mathrm{TM}}$ HRP substrate, \#WBKLS0500, Millipore Corp., MA, USA).

\section{HEK-293 \\ derived EVs}

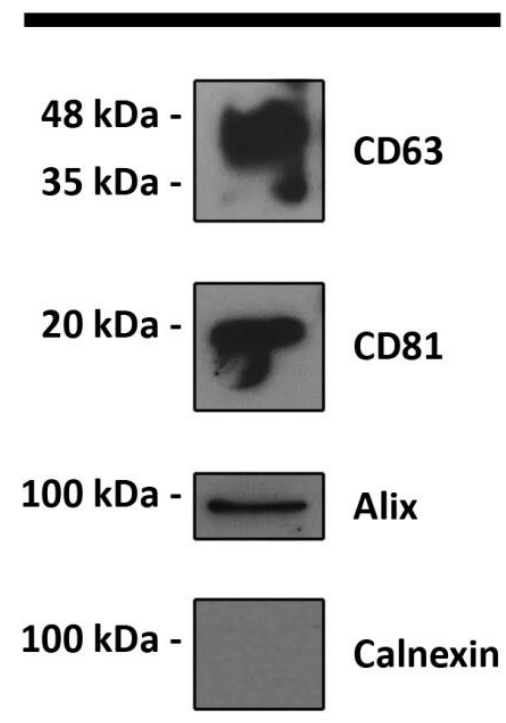


Figure S2. Western Blot analysis of EVs isolated from HEK-293 cell culture media by ultracentrifugation.

3.3 TEM Microscopy: Transmission electron microscopy (TEM) was performed on isolated EVs, resuspended in PBS, to analyze their ultrastructural morphology. According to proper dilution, the sample was adsorbed to 300 mesh carbon-coated copper grids (Electron Microscopy Sciences, Hatfield, PA, USA) for $5 \mathrm{~min}$ in a humidified chamber at room temperature. EVs on grids were then fixed in $2 \%$ glutaraldehyde (Electron Microscopy Sciences, Hatfield, PA, USA) in PBS for $10 \mathrm{~min}$ and then briefly rinsed in milli-Q water. Grids with adhered SEVs were examined with a Philips CM 100 transmission electron microscope TEM at $80 \mathrm{kV}$, after negative staining with $2 \%$ phosphotungstic acid, brought to $\mathrm{pH} 7.0$ with $\mathrm{NaOH}$. The images were captured by a Kodak digital camera.

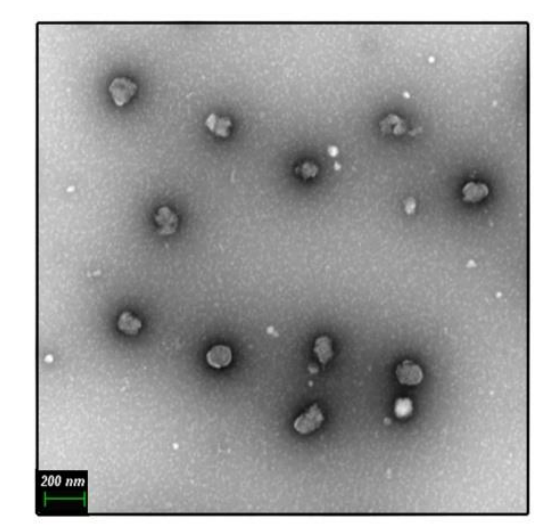

Figure S3.TEM microscopy image of EVs isolated from HEK-293 cell culture media by ultracentrifugation. Scale bar indicates $200 \mathrm{~nm}$. 
Separation of extracellular vesicles by DNA-directed im... (111.24 KiB) view on ChemRxiv • download file 